Portland State University

PDXScholar

1972

\title{
Psycho-social Aspects of Acute Lymphocytic Leukemia in Children
}

\author{
Sally Myers Hingley \\ Portland State University \\ Judith Ann McKay \\ Portland State University
}

Follow this and additional works at: https://pdxscholar.library.pdx.edu/open_access_etds

Part of the Social Work Commons

Let us know how access to this document benefits you.

\section{Recommended Citation}

Hingley, Sally Myers and McKay, Judith Ann, "Psycho-social Aspects of Acute Lymphocytic Leukemia in Children" (1972). Dissertations and Theses. Paper 1617.

https://doi.org/10.15760/etd.1616

This Thesis is brought to you for free and open access. It has been accepted for inclusion in Dissertations and Theses by an authorized administrator of PDXScholar. Please contact us if we can make this document more accessible: pdxscholar@pdx.edu. 
AN ABSTRACT OF THE THESIS OF Sally Myers Hingley and Judith Ann McKay for the Master in Social Work presented May 19, 1972.

Title: Psycho-social Aspects of Acute Iymphocytic Leukemia in Children.

APPROVED BY MEMBERS OF THE THESIS COMMITTEE:

Jack C. Finley, Chairman

Robert D. Goldman

The purpose of the study was to assess psycho-social differences between two groups. A review of the literature suggested psychological and social factors may affect the onset and progression of malignant disease. Comparisons were made between a group of 23 experimental families with a leukemic child, and a group of control families with a normal child matched for child's sex, age, and number of siblings. Datawas gathered on three quantifiable measures;

Coddington's Social Readjustment Rating Questionnaire, a specially constructed Child's Questionnaire, and The Minnesota Multiphasic Personality Inventory. 
The leukemic children and their matched normal controls had approximately equal numbers, and similar types, of social events that had occurred within their present life span. This suggests that the occurrence of a specific stressful life event is not, in itself, a major precipitating factor in onset of leukemia.

The leukemic children and their normal controls were likewise similar in their responses concerning self-reported aggressive behavior and attitudes toward expression of aggressive feelings. This implies that, other than the presence of disease, the leukemic children respond to specific stimuli in a manner typical of normal children.

The parents of the leukemic children however, were differentiated from the parents of normal children, through the statistical method of stepwise discriminant analysis of MMPI responses. A combination of five variables, for each pair of parents, father's Sc 0 (Si) score, mother's Sc 1 (Hs) score, and father's Sc 9 (Ma), F scale, and Sc 3 (Hy) scores, had a level of significance. This finding presents evidence that parents of leukemic children differ from parents of normal children on personality characteristics assessed by the MMPI. Some possible interpretations of these results, and suggestions for treatment and additional research, were offered. 
TO THE OFFICE OF GRADUATE STUDIES:

The members of the Committee approve the thesis of

Sally Myers Hingley and Judith Ann McKay, presented May 19, 1972.

Sack C. Finley, Chairman T

Robert D. Goldman

APPROVED:

Gordon Heaf

David T. Clark, Dean of Graduate Studies

May 19, 1972 
PSYCHO-SOCIAL ASPEC TS OF ACUTE LYMPHOCYTIC

LEUKEMIA IN CHILDREN

by

Sally Myers Hingley

Judith Ann McKay

A thesis submitted in partial fulfillment of the requirements for the degree of

MASTER OF SOCIAI WORK

Portland State University

1972 


\section{ACKNOW LEDGMENTS}

Sincere appreciation is extended to the many individuals who assisted the writers in the preparation of this thesis.

We wish to express our thanks to Mr. Art Stein, Principal of Ardenwald Elementary School and his secretary, Mrs. Barbara Bizeau, Dr. Paul Muno, Dean of Boys, Milwaukie High School and Mrs. Frances Ousley, Director, Fruit and Flower Day Nursery for their help in facilitating the gathering of the control data for this thesis. Also, special regards is given to the families who participated in the study for their cooperation in completing the data.

We are particularly grateful to Mr. Jack Finley, Thesis. Chairman, who guided us through the completion of this thesis and Dr. Robert Goldman, Thesis Committee Member, without whose advice and encouragement we would not have undertaken this project.

Special acknowledgment is given to Dr. Horace M. Manning for his help in the use of the MMPI and to Dr. Quentin D. Clarkson and Dr. Ephriam Peretz for their valuable help in statistical procedures. Finally, special thanks go to Jane Hoxsey who keypunched our data cards and to Noel Hingley who consistently came to our aid with meral support. 
TABLE OF CONTENTS

PAGE

ACKNOW LEDGMENTS

iii

LIST OF TABIES

vi

THEORETICAL INTRODUCTION

1

STATEMENT OF THE PROBIEM 10

$\begin{array}{ll}\text { HYPOTHESES } & 15\end{array}$

EXPERIMENTAL SUBJECTS $\quad 17$

CONTROL SUBJECTS 21

METHODOLOGY 24

Minnesota Multiphasic Personality Inventory 26

Social Adjustment Rating Questionnaire 28

Child's Questionnaire 31

ANALYSIS AND INTERPRETATION OF RESULTS 34

Descriptive Data $\quad ~ 34$

Child's Questionnaire 41

Social Event Rating Questionnaire 45

Minnesota Multiphasic Personality Inventory 47

DISCUSSION $\quad \because \cdots \cdots$ 
$\begin{array}{lll}\text { Appendix A Child's Code Sheet } & 73\end{array}$

Appendix B Parent's Code Sheet $\quad 77$

Appendix C Data Cover Letter 80

Appendix D Social Readjustment Rating Questionnaire as Presented to Subjects

Appendix E Child's Questionnaire, True-False Coded for Active-Passive Response

Appendix F Social Readjustment Rating Scale: Ranks, Life Events, Life Change Units and Item Frequencies by Group

Appendix G Social Adjustment Rating Questionnaire: Total Scores by Case Number and Group 92

Appendix H Frequency Distribution of Social Adjustment Rating Questionnaire: Fourteen Object Loss Events by Age and Group

Appendix I Results of MMPI Scale Scores by Parent and Group: Means and Standard Deviations 
LIST OF TAB LES

TABLE

PAGE

I Description of Experimental Subjects:

Case Number, Sex, Age, Age at Diagnosis,

Survival Time

18

II Frequency and Percentage Distribution of

Experimental Subjects by Year of Diagnosis

III Frequency and Percentage Distribution of

Experimental Subjects by Number of

Siblings

20

IV Frequency and Percentage Distribution of

Total Family Income for 1971 by Group

22

V Frequency and Percentage Distribution of Birth

Order by Sex and Group

VI Frequency and Percentage Distribution of Child's

Living Arrangements by Group

VII Frequency and Percentage Distribution of Marital

Status by Parents and Group 
VIII Frequency and Percentage Distribution of

Employment Status by Parent and Group

IX Frequency and Percentage Distribution of

Parent's Age by Group with Means 40

Xa Item Analysis of True-False Responses on

Child's Questionnaire Part I Showing Active-

Passive Code, With-In Group and Between Group

Variance

$\mathrm{Xb}$ Item Analysis of Agree-Disagree Responses on

Child's Questionnaire Part II Showing Active-

Passive Code With-In Group Variance and

Between Group Variance

44

XI Stepwise Discriminate Analysis of Ten Variables;

Means, Standard Deviations by Group; Grand

Means, F Values, Degrees of Freedom, P

Values

49

APPENDIX TAB LES

XII Social Readjustment Rating Questionnaire; Ranks, Life Events, Life Change Units and Item

Frequencies by Group 
XIII Social Adjustment Rating Questionnaire; Total

Scores by Case Number and Group

XIV Frequency Distribution of Social Adjustment

Rating Questionnaire; Fourteen Object

Loss Events by Age and Group

XV Results of MMPI Scale Scores by Parent and

Group, Means and Standard Deviations 


\section{THEORETICAL INTRODUCTION}

Conceptual formulations regarding the nature of the relationship between mind and body, are varied and numerous. A quick review of Alexander and Selesnik's, The History of Psychiatry (1966), reveals that theoretical formulations and treatment modalities have varied from an essentially unitary approach characteristic of many early primitive societies, to the highly separatist approach favored in medicine some decades ago. Modern ideas imply that all functioning, healthy and sick, is both physiological and psychological. An implication of vital etiologic and preventative import is the manner in which they physiologically and psychologically relate to each other, or more

specifically, their relative importance in causation of illness. There are some diseases such as asthma, colitis, peptic ulcer, hypertension, which, while manifested organically, are usually recognized to be of primarily psychologic origin. Others, such as hysterical paralysis and blindness are regarded as solely psychological. Then there is that catagory of illness, exemplified by organic brain damage and various toxic states, which are physiologically "caused" but result in psychological-like symptoms. And finally, there are those illnesses, 
of organic causation and symptomology, such as influenza, measles, cancer, etc.

By far the large majority of illness is categorized as being either of physiologic (heredity, constitution, disordered chemistry, infection), or psychologic (trauma, stress, repressed emotions, faulty relationships) etiology. This practice is seen as a simple, but rigid and artificial categorization stressing single factors in causality of disease. Clinicians and researchers are increasingly rejecting old ideas of single factor causality, and are recognizing that a multiplicity of factors are implicated in the initiation, propagation, outcome, and therapy of disease. (Kissen, 1966a; Blumberg, West and Ellis, 1954; Bard, 1966).

It is no longer a question of how the physical affects the psychological, or vice versa, but more a matter of how they interrelate as ,

an integrated system with the total environment. An hereditary "cause" implies some genetic predisposition to a disease, yet it is now recognized that some environmental stimulus is often needed to bring the hereditary predisposition into action (Moraczewski, 1970; Wolff, 1950). There is also a growing awareness, that while the stimulus may be of organic origin, such as a known carcinogen, it may also be psychologic. An example would be the "anniversary syndrome," where there is an expectation, and a predisposition for, coronary thrombosis, psychological depression, etc., from which a significant member of 
the family suffered in the past, and which the patient later manifests when he reaches the same age (Grinker, 1966b).

Constitutional factors are no longer regarded as fixed and static predispositions, but as factors which may shift and change with age and stimuli (Grinker, 1966b). However, clinicians generally agree. that it is during an individual's early years, that the mental and physical structures and functions of the body are most plastic and mallable (Spitz, 1945). It is thus during this time that the most drastic and extensive effects on constitution may be achieved. The research of Spitz (1965), later supported by Harlow's (1965) experiments with infant monkeys, graphically reveals the extent to which maternal separation can inhibit an infant's psychological and physical development.

The physical effects of such factors as poor maternal nutrition on the subsequent physical development of the infant are well known, $\checkmark$

as are the psychological effects of an alcoholic parent on the child. Additionally, many clinicians acknowledge that a child's early psycho-

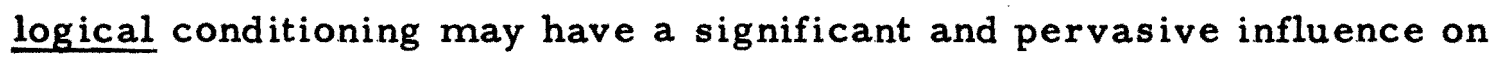
both psychological and somatic functions (Grinker, 1966b). That early psychological conditioning can exert tremendous influence on somatic functions in later life is best exemplified by cases of "Voodoo Death." Here psychological conditioning, resulting from cultural learning, precipitates a breakdown of somatic functioning that ultimately results in death (Weiss, 1969). Ia Barba (1970) in his review of animal 
research on experiential and environmental factors in cancer, reports that the duration and type of environmental stress can significantly influence the progression of the disease.

While psychosocial factors are limitedly recognized, there is considerable controversy, regarding classification of the "psychophysiological" disorders (those diseases with a recognizable psychological component), and the extent to which psychological states affect physical health and disease. This controversy is largely a result of the misconception that a psychosomatic approach to disease is oriented toward finding the psychological cause, to the exclusion of somatic factors (Grinker, 1966b). Rather, "psychosomatic" should be considered as an approach attempting to differentiate phases of somatic and psychologic processes and the means through which they affect each other (Kissen, 1966a). In this view there may be predisposing causes, precipitating causes and perpetuating causes, variously influencing the expression of disease during different times.

An increasing array of diseases are being examined for their psychological components. Medical clinicians have long observed-the influence of cancer upon the patient's psychologic functioning (Calloway 1952; Renecker and Cutler 1952; Shands, 1966). Now, within the last two decades, clinicians are also becoming more aware of the influence of the psyche on the clinical course of cancer (Bard, 1966), and even in relation to the onset of disease (Corson, 1966; Newton, 1964). 
Blumberg, et al. (1954), utilizing the MMPI, compared personality characteristics of long surviving cancer patients and those with rapidly advancing disease. They found significant differences between the two groups which suggested that long-standing, intense emotional stress may stimulate the growth rate of clinically established cancer.

Research into the psychosomatic aspects of cancer has resulted in two main theoretical trends. One group of workers observe that separation, and object-loss, with feelings of despair, depression and hopelessness, are important precursors in manifest development of clinical cancer. The loss-depression hypotheses revolve around the nature of the patient's life history, the quantity and quality of events. There is a vast literature on the association of separation experiences and onset of disease. Greene, a pioneer in psychosomatic research, relates that leukemias and lymphomas often occur during a time when i the patient is dealing with a loss or separation from significant objects or goals and is overcome with feelings of hopelessness (Green, Young and Swisher, 1956; Green, 1966). Another group lead by LeShan, suggest that cancer patients are characterized by a depletion of energy resulting from a life of desertion, loneliness, guilt and self-condemnation (LeShan and Worthington, 1956a, 1956b; LeShan and Reznikoff, 1960; LeShan, 1966). LeShan went on to note that his patients continued to carry out their usual activities and responsibilities, but achieved little satisfaction, and tended to give more to others than they received. 
Schmale (1958) and Schmale and Iker (1964) studied the relation of separation and depression to development of uterine cervical cancer. He correctly predicted cancer diagnosis in 36 out of 51 cases on psychological characteristics alone. His predictions were based on life histories which showed that a woman had responded to a life event with feelings of hopelessness within the last six months prior to the first positive PAP smear. Kissen (1966c; Kissen, et al. 1969) reports that a lung cancer patients report adverse life situation as children and adults, significantly more often than control patients. Muslin, et al. (1966) also note that separation experiences from lifesaving dependent relationships frequently antedates the appearance of cancer. Dr. Schmale (1964) explains the operation of the separationdepression theory, by suggesting that the patient's reaction of hopelessness to a loss should be seen as a "permissive or facilitating factor $\therefore$ that allows the cancer as well as other diseases to appear when they do." He thus feels the psychological factors operate as a nonspecific factor in initiating a predisposition to cancer to become manifest.

While a significant object-loss is a readily apparent phenomenen in cancer-personality studies, many researchers have noted that most people experience loss or separation and depressive states without the concomitant development of malignancy. This observation has lead some workers to investigate the cancer patient's idiosyncratic interpretation of loss and his characteristic coping mechanisms. 
This second set of hypotheses, termed "Ego Defense Theories," focus on coping patterns and structure of personality, having their antecedents in early experiences. Thus, Bahnson and Bahnson (1969) hypothesize that the observed loss preceding the exacerbation of clinical manifestation of cancer should be understood as a special variety of loss experience based on a history of childhood affective deprivation. He feels that only with great effort could cancer patients maintain even an unsatisfying, primitive, and uncertain relationship with their parents. Adolescent separation was painful and perceived as severe deprivation. Substitute emotional investment in a subsequent relationship, object, or work, was difficult because of the child's mistrust and hostility. When the precariously established substitute relationship or investment breaks down in adulthood, the patient feels the original despair and hopelessness, and idiosyncratically believes , little help can be obtained from others, and so turns inward toward himself and gives up trying to interact emotionally with other people. Bahnson (1969) feels that this hopelessness sets the stage for regression. However, as the cancer patient has lived for years with an ungratifying reality, he is able to maintain realistic relationships with society and will not show behavioral regression. Rather, the regression is manifested somatically, in the form of illness.

Greene and his co-workers in a series of articles $(1956,1958$, $1959,1966)$ in a similar vein, noted that women with lymphomas and 
leukemias commonly reacted to separation and loss by identifying with, and introjecting the lost object, while denying emotion and dependency needs. In a later extension of these studies, Green (1969) presented a theory relating development of childhood leukemia to a change in the child's role as a vicarious (substitute) object for a significant person, usually the mother. Kissen, in his studies with lung cancer patients, comments on their characteristic inhibition, blandness, denial, and tendency to suppress emotional problems and conflicts, stating cancer patients have a "diminished outlet for emotional discharge" (Kissen \& Eysenck, 1962; Kissen, 1964a; 1964b, 1965, 1966a, 1966b, 1966c; Kissen \& Rao, 1969). Booth (1969) in personality comparisons of tuberculosis and cancer patients, concluded that the cancer patient is typically emotionally isolated and autistic. Bahnson and Bahnson (1969), in a study of ego defenses, found that cancer patients ? tend to repress and deny unpleasant affect such as anxiety, hostility, or guilt, more often that matched control subjects. Henderson (1966) showed how denial of symptoms and malignancy by patients resulted in dangerous or fatal delay in initiation of treatment. Cobb (1952) also commented on the extreme denial characteristics of cancer patients. In essence, researchers have indicated that there are,presumably, marked differences in the cancer patient's handling of stressful environmental stimuli. 
In partial summary, it may be said that there are ipdications that personality factors may be linked with the presence and rate of progression of clinical cancer. In general terms, these factors are usually related to some sort of environmental stress, and the patient's unsuccessful psychological defenses. In Solomon's (1969) analysis of personality studies with cancer patients, three consistent factors were mentioned. These were: (1) the patient's loss of an important relationship prior to the onset of disease, (2) the cancer patient's inability to express hostile emotions, and (3) the patient's unresolved feelings and relationship with a parent. 


\section{STATEMENT OF THE PROBLEM}

While a review of the literature on the psychosomatic aspects of cancer suggests there may be a relationship between psycho-social factors and manifest development of disease, many of the studies are subject to certain methodological criticisms. An often noted deficiency of some studies is the use of a small number of subjects from which random and arbitrary results and tenuous theoretical conclusions are then generalized to the population as a whole. Selection of cancer patients is sometimes made without reference to the type and approximate duration of the disease. There is a noticeable lack of studies utilizing control groups, and those that do, often inadequately define the population, and have faulty sampling. (Perrin and Pierce, 1959; LeShan, 1959; LeShan and Worthingt on, 1955).

More objective measures and standard, codeable interview techniques are needed (Kissen, 1960).. Most studies based on personality tests utilize very subjective instruments such as the Rorschach and the TAT. Interview methods are not specified, and historical data and situational observations are frequently elicited by different inter viewers. Kissen (1968) reported findings that different interviewers reported different results, especially in situations where the questions 
were read to the subject. A difficulty in interpreting and generalizing data results from the vague, undefined, and arbitrary use of terms such as "loss of object," "diminished emotional discharge," etc., resulting in a jungle of jargon.

Central to these issues are the inherent problems present when dealing with subjective psychological processes, such as the perception of social events, and their interactions with objective material systems, such as a malignancy. These methodological problems are intensified when dealing with young children, inexperienced in language and reading skills, and are no doubt responsible for the dearth of material on psychological factors in childhood malignancy. It would seem imperative that childhood malignancies be investigated in reference to the psychosomatic aspects of cancer (Ariel and Pack, 1960). Invariably, adult cancer-personality studies make reference to early patterns initiated in the subject's childhood, as setting the stage for later malignant disease. The child with leukemia presents a somewhat unique situation. Here the time span between birth and onset of cancer is greatly compressed, and the number of possible intervening variables is reduced.

Additionally, adult cancer studies, report on the parent-child relationship, parental attitudes toward the child, parental perception of significant events, etc., yet rarely are the parents of the adult cancer patient directly assessed. Bozeman, Sutherland, and Orbach 
(Bozeman, et al. , 1955; Orbach, et al. , 1955) reported the first systematic investigation of interpersonal and psychological variables in relation to leukemia children. They noted that mothers of leukemic children may have a disturbed relationship with their own mothers, and suggested the meaning of the leukemic child in the mother's life be studied. In 1958, Greene and Miller conducted and extensive analysis of leukemic child-parent relationships based on observations of 33 children. He found the children had experienced various types of loss prodromal to apparent disease onset. In a later study, Greene (1959) developed a theory in which the leukemic child serves as a vicarious (substitute) object preventing depression in the mother. With additional losses and disappointments the mother gives up the child as a vicarious object and becomes psychologically depressed. It is after this change in the mother-child relationship that the child's manifest leu,

kemia develops. Greene feels that leukemia is just one of the many possible somatic manifestations that may develop, and that it is determined mainly by biological characteristics of the individual.

While Greene's studies represent monumental work in the area of childhood leukemia, they are subject to many of the methodological criticisms stated previously. The present study is an attempt to supplement and validate aspects of prior research with leukemic children. Although it is extremely difficult to control intervening variables 
and overcome many methodological problems (Bennette, 1969), some refinement has been possible.

The current study involved a total known population of living leukemic children during a specified time period, and with identical diagnoses. This decreased possible selection bias and provided a fairly large number of subjects. A control group was carefully drawn from a defined population and matched with respect to child's age, sex, and number of siblings. Age and sex matching is a common control procedure. The number of siblings was defined as an important control variable due to the observation that the leukemic group was characterized by a preponderance of two sibling families (14 out of 23). Greene and Miller (1958), in a review of literature, reported a disproportionately large number of leukemic first-born children and twins in a study of 1500 cases. Many writers have discussed the ims portance of sibling number and birth order, on personality characteristics. Harris and Howard (1968), Palmer (1966), and Grossman \& Eisenman (1972), found that first borns more effectively internalize parental standards, demonstrating greater compliance with moral injunctions and adult expectations that later borns. First borns were found to display the greatest identification with the parents. Additionally, Weiss $(1968,1970)$ presented some evidence for a relationship between birth order and the subject's physiological response to stress. 
He felt his results pointed to the importance of controlling birth order in behavior studies which may be affected by the variable.

All current data was derived from objective measurements. These measures are objective in the sense that they may be standardly quantified. However, the subjective quality of subject response, always present in any "objective" test, should be recognized. Material was gathered by two social workers, each contacting a random half of both groups, thus decreasing interviewer effects. 


\section{HYPOTHESES}

The study, although primarily exploratory and descriptive, permits the testing of a general hypothesis. It is thus predicted that there will be significant psychological and social differences between the experimental leukemia families and the normal control families. The methodology employed enables the general hypothesis to be operationally expressed in the following way.

1) The parents of leukemic children as a group will differ significantly from the normal control parents on MMPI profile scale scores.

2) The experimental leukemic children will achieve a higher total score on the Social Event Rating Questionnaire than their matched normal controls.

3) There will be a significant difference between the two groups in the reporting of an "object loss," on the Social Event Rating Questionnaire. The leukemic group will report a significantly greater number of these events than the normal group. Items categorized as an object loss are: Birth of a brother or sister; Serious illness requiring hospitalization of parent; Change in father's occupation requiring increased absence from home; 
Divorce of parents; Marital separation of parents; Death of a borther or sister; Jail sentence of parent for one year or more; Marriage of parent to stepparent; Discovery of being an adopted child; Death of a grandparent; Mother beginning to work; Death of a close friend; Death of a parent; Move to a new school district. It may be seen that "object loss" refers to the loss of an "object" in the child's environment, and to a change in the child's status as an "object" himself.

4) There will be differences between the leukemic and control children in answering patterns on the Child's Questionnaire. The leukemic group will show more agreement on questions than the controls. The leukemic group will self-report less overt, active and direct expression of aggressive and hostile feelings than the control group. 


\section{EXPERIMENTAL SUBJECTS}

All known living children diagnosed as leukemic in Oregon, and living as of October 1971, and all new cases diagnosed up to February of 1972 , were approached for participation in the study. This yielded an original sample of 26 cases, of which, one subject died before data was collected, one subject moved, and one subject did not complete the data. The final sample thus consisted of 23 leukemic children and their parents.

The usual hematological diagnostic procedures including bone marrow examinations, were used to obtain data on diagnosis. All 23 subjects were diagnosed with acute lymphocytic leukemia. Eleven 'subjects were boys and twelve were girls. Ages, as of March 1972, ranged from 2 years. 7 months to 15 years 11 months, with a mean age of 7 years 10 months as of March 1972. Age at diagnosis varied from 3 months to 15 years, with current survival times, as of March 1972, varying from 2 months to 6 years 6 months. Data on sex, age, age at diagnosis, and survival time is shown in Table I. It should be noted that the time of onset of disease may occur weeks, months, or years before actual diagnosis is made. Therefore, current survival times. may be somewhat misleading. Table II presents the distribution of 
TABLE I

DESCRIPTION OF EXPERIMENTAL SUBJECTS: CASE NUMBER, SEX, AGE, AGE AT DIAGNQSIS, SURVIVAI TIME

\begin{tabular}{|c|c|c|c|c|}
\hline Case Number & Sex & $\begin{array}{c}\text { March } 1972 \\
\text { Age }\end{array}$ & $\begin{array}{c}\text { Diagnosis } \\
\text { Age }\end{array}$ & $\begin{array}{c}\text { March } 1972 \\
\text { Survival Time }\end{array}$ \\
\hline 122 & $\mathbf{F}$ & 2.7 & 2.1 & .6 \\
\hline 124 & $\mathbf{M}$ & 2.8 & 2.2 & .6 \\
\hline 116 & $\mathbf{F}$ & 3.6 & 2.4 & 1.2 \\
\hline 125 & $\mathbf{F}$ & 4.2 & 4 & .2 \\
\hline 106 & $\mathbf{F}$ & 4. 9 & 3.2 & 1.7 \\
\hline 107 & $\mathbf{F}$ & 4.11 & 4.9 & .2 \\
\hline 103 & $\mathbf{M}$ & 6.11 & 6 & .11 \\
\hline 114 & $\mathbf{M}$ & 7.3 & 6 & 1.3 \\
\hline 119 & $\mathbf{F}$ & 7.4 & 6.6 & .10 \\
\hline 109 & $\mathbf{M}$ & 7.7 & 7.5 & .2 \\
\hline 112 & $\mathbf{F}$ & 7.11 & 3 & 4.11 \\
\hline 121 & $\mathbf{M}$ & 7.11 & 6.10 & 1.1 \\
\hline 108 & $\mathbf{M}$ & 8.6 & 7.2 & .6 \\
\hline 101 & $\mathbf{F}$ & 8.7 & 8.3 & .4 \\
\hline 105 & $\mathbf{M}$ & 8.10 & 7.7 & 1.3 \\
\hline 115 & $\mathbf{M}$ & 9.7 & 4.9 & 4.10 \\
\hline 110 & $\mathbf{F}$ & 9.8 & 6.8 & 3 \\
\hline 113 & $\mathbf{F}$ & 10.3 & 3.9 & 6.6 \\
\hline 111 & $\mathbf{F}$ & 10.11 & 10.3 & .8 \\
\hline 117 & $\mathbf{F}$ & 13.11 & 10.4 & 3.7 \\
\hline 104 & $\mathbf{M}$ & 15.3 & 15.1 & .2 \\
\hline 102 & $\mathbf{M}$ & 15.7 & 9.3 & $4.4 *$ \\
\hline 118 & $\mathbf{M}$ & 15.11 & 12.8 & 3.2 \\
\hline
\end{tabular}

This subject expired October, 1971. Therefore his survival time is actual. 
subjects relative to the year of diagnosis. The shorter current survival time of the later diagnosed children is not a result of progression. of disease, but rather due to the data of diagnosis.

\section{TAB LE II}

FREQUENCY AND PERCENTAGE DISTRIBUTION

OF EXPERIMENTAL SUBJECTS BY

YEAR OF DIAGNOSIS

\begin{tabular}{lcc}
\hline Year & Frequency & Percent \\
\hline 1965 & 1 & $(4)$ \\
1966 & 1 & $(4)$ \\
1967 & 2 & $(9)$ \\
1968 & 3 & $(13)$ \\
1969. & 0 & $(0)$ \\
1970 & 4 & $(17)$ \\
1971 & 8 & $(36)$ \\
1972 & 4 & $(17)$ \\
& $23=\mathrm{N}$ & $(100)$ \\
\hline
\end{tabular}

The number of siblings for each experimental leukemic child, is presented in Table III; ranged from one to six. A great majority, 14 out of 23 , of the leukemic children had only one brother or sister. While we feel this may be an important variable, the effects of sibling number were controlled, in order to investigate potential effects from other variables. 
TABLE III

FREQUENCY AND PERCENTAGE DISTRIBUTION

OF EXPERIMENTAI SUBJEC TS BY

NUMBER OF SIB LINGS

\begin{tabular}{ccc}
\hline Number of Siblings & Frequency & Percent \\
\hline 1 & 14 & $(61)$ \\
2 & 4 & $(17)$ \\
3 & 2 & $(9)$ \\
4 & 2 & $(9)$ \\
5 & 0 & $(0)$ \\
6 & 1 & $(4)$ \\
& $23=N$ & $(100)$ \\
\hline
\end{tabular}

All of the leukemic children were Caucasian. The leukemic families displayed a fairly even income distribution (see Table IV), and lived predominantly in suburban areas, with a few from semi-rural areas. 


\section{CONTROL SUBJECTS}

The normal control subjects consisted of 23 children, age 2 to 15, randomly chosen from representative schools in the greater Portland metropolitan area, and their parents. The sample schools were characterized by students from a wide range of income brackets, and from semi-rural or suburb areas, thus randomizing the effects of income and socio-economic status. However, one sample school, the "Fruit and Flower" Nursery and Preschool, from which the 2-5 year olds were drawn, may be considered somewhat unrepresentative. As with most preschools, a number of the children at "Fruit and Flower" had mothers who were divorced or widowed, and were working in Portland. The school does represent a diverse range of incomes, as payment is based on a sliding fee scale, and children are brought in each morning from a variety of areas. The 6-12 year old control subjects were drawn from Ardenwald Grade School, and the 13-15 year old controls from Milwaukie High School. Income distribution for the control families is presented in Table IV. The average yearly income, as illustrated for the control subjects, is somewhat unreliable as precise figures were unavailable. Parents were asked to report their average yearly income from all sources to the interviewer, 
which may have resulted in data being skewed toward the higher figures.

TABLE IV

FREQUENCY AND PERCENTAGE DISTRIBUTION

OF TOTAL FAMILY INCOME FOR

1971 BY GROUP

\begin{tabular}{|c|c|c|c|c|}
\hline \multirow[b]{2}{*}{ Income } & \multicolumn{2}{|c|}{ Experimental Group } & \multicolumn{2}{|c|}{ Control Group } \\
\hline & Number & Percent & Number & Percent \\
\hline Under $\$ 3,999$ & 4 & (17) & 4 & (17) \\
\hline$\$ 4,000-\$ 5,999$ & 3 & (13) & 3 & (13) \\
\hline$\$ 6,000-\$ 7,999$ & 3 & (13) & 2 & (9) \\
\hline$\$ 8,000-\$ 9,999$ & 5 & (22) & 5 & (22) \\
\hline$\$ 10,000$ and over & 8 & (35) & 9 & (39) \\
\hline Totals & 23 & $(100)$ & 23 & $(100)$ \\
\hline
\end{tabular}

$\because \quad$ "Between sample matching" was employed with the two population groups. By this method, the two groups were defined and formed first, and then matched pairs formed in relation to one or more variables. Control names were randomly pulled until a match was found with a leukemic child. In this particular study the relevant variables selected and controlled were: child's sex and age ( $₫ 6$ months), and number of siblings in the family. Control subjects who were not Caucasian, or who had a chronic disease (e.g. epilepsy) or severe physical deformity, were discarded. 
In one case (\#104), a match was not found for a leukemic child. A control family ( $\$ 220)$ had originally been discarded, as the matched leukemic child had died prior to completion of the study. The parents of \#104 and \#220 were similar in parental age, income, marital status, and family size, and were therefore used as a matched parental pair. The identified children of each case were of the same sex, but had a 5 year age difference. Therefore, the Social Event Rating Scale and Child's Questionnaire of another control child of the same sex and age (\#218), was used for \#104's matched child control. Thus, on the. Social Event Rating Scale and Child's Questionnaire, one set of control data is used twice for two different leukemic children. This method prevented the discarding of one set of leukemic data, but does introduce some problems as the twice used control child had a rather atypical response pattern on the child's questionnaire. : 


\section{METHODOLOGY}

The experimental and control groups were administered identical data over a six month time period. This consisted of: the MMPI (Minnesota Multiphasic Personality Inventory) completed by both the mother and father, Coddington's Social Readjustment Rating Questionnaire filled out by both parents in reference to the identified child (leukemic or matched control), and a short que stionnaire administered to those leukemic children and their matched controls age six and over. One of the researchers administered data to a random half of both the experimental and control groups, while the other researcher administered to the remaining halves.

$\therefore \quad$ The experimental families, were written a letter of introduction by the attending physician. They were then contacted over the telephone by the researchers, and an appointment made to explain the study during the child's regular check-up visits to the Hemotology Clinic at the University of Oregon Medical School, or in their home. Participation was voluntary and confidential. The purpose of the study was explained as an attempt to understand some of the psychological (emotional) and social aspects of the disease, and how it affected them as a family unit. Results would be used to better understand 
the problems they face, the child's interaction with his friends, and in what way professionals may best help them. The measurements were then explained to them, and left for them to complete at their leisure at home. Arrangements were made for them to return the data to the medical school, either in person or by mail, or for a researcher to return to pick it up.

The selected control families were written a letter of introduction by the school's Principal or Dean of Boys. They were then telephoned by the social worker ahd an appointment made to explain the study in their home. Participation was, again, voluntary and confidential. Some of the problems leukemic families face (e.g. medical expenses) were explained to the controls. They were told that one of their children had been randomly selected through the school and matched with a leukemic child. The purpose was to compare a group of leukemic families with a group of normal families, which they represented. It was hoped the comparison would show that there are differences in the quantity and quality of social experiences that the leukemic families have had to face, and how this affects them emotionally. In this manner we hoped to identify the areas of potential problems, and provide the leukemic families with help where needed. The measures were then explained to them and arrangements made to pick up data when completed. 


\section{MINNESOTA MULTIPHASIC PERSONALITY INVENTORY}

The MMPI was chosen for administration as it is one of the most well known, widely used, and extensively researched (validated) objective personality measurement. It has been utilized in a number of cancer and personality studies, notably those of Blumberg (1954), and Moos \& Solomon (1965), and thus may furnish some basis for comparison of studies. The preponderance of cancer studies used the MMPI as a measure of the cancer patient's personality character istics. In the present study however, the young age of the majority of the subjects precluded direct testing of their responses. The MMPI was therefore administered to the subject's parents on the basis of two assumptions.

The first of these assumptions was that the subject's personality and methods of coping with stress, will reflect that of his parents' to a significant degree, within his own genetic limits. "Personality" is here defined as the individual's typical mode of reaction to his internal and external environment. This first as sumption reintroduces the long standing nature-nuture controversy relating to personality development. It is our feeling that there are inherent personality differences and individual reactions to stimuli even among genetically similar organisms (siblings). These variations however, may be strongly modified through the process of identification and modeling 
with the parents (Harris \& Howard, 1968; Palmer, 1966). A given child therefore, may "learn" that proximity of a live rodent constitutes a "stress" situation, if the mother herself regards it as such. Or, a normally aggressive child may learn to either severely prohibit, or to allow full expression of, his aggressive impulses, in accordance with his parent's attitudes and behavior (Grossman \& Eisenman, 1972). In this manner an assessment of parental personalities may give some indications of influences upon the child's own developing personality.

A second assumption regarding use of the MMPI is, that although some individual scale scores, such as "depression," will vary extensively over time and with mood, the characteristic profile will remain relatively stable in certain aspects. An obvious criticism of any afterthe-fact assessment of variables, is to what extent results reflect prodromal factors as opposed to those resulting directly from the stimulus situation. As such, any significant differences between the leukemic and control group on MMPI scales may possibly be attributed to stressful situational factor's (i. e. child diagnosed leukemic). Parents of the leukemic children were administered the MMPI only after the acute shock of diagnosis had time to dissipate somewhat (generally from 1-6 months), and at a time when the child was in remission, or free of acute disease symptoms. Additionally, the test was self-completed at their leisure, in private and away from the hospital environment. 
By these methods it was hoped that situation of stress was at a low level, and not as likely to extensively influence test responses.

An important aspect of current situational influencès on parental MMPI responses is the possible similarity to past stress reaction patterns. In this view, parent's response to a current crisis, as reflected in the MMPI profile, is seen as basically similar to his probable reactions to past crises, and thus may reflect a relatively stable pat-. tern of coping. This may reveal how past crisis were dealt with by a parent, and by extrapolation, how past crises were perceived and reacted to by the child.

\section{SOCIAL READJUSTMENT RATING QUESTIONNAIRE}

To determine the nature and extent of past situations which required coping behavior on the part of the identified child, Coddington's Social Readjustment Rating Scale was administered to both groups. Coddington's scale was an adaptation of the Schedule of Recent Experiences, developed originally by Dr. Thomas Holmes and co-workers. This was a method of quantifying the significance of various life events as they occur in the adult population (Holmes and Rahe, 1967, Masuda and Holmes, 1967). Holmes and Rahe (1967) had found that too many life changes, both positive and negative, occurring too close together, often preceded grave illness or depression (Holmes, 1968; Rahe \& Arthur, 1968). The schedule of Recent Experiences is a list of 43 
life events found to cluster around time of physical disease onset (Hawkins, Davis, and Holmes, 1957), and that necessitates some degree of adaptation on the part of the person involved (Rahe, Meyer, Smith, Kjaer and Holmes, 1964). The degree of adaptation required for each event was quantified using the method of magnitude estimation. Each event is additive, with the patient's yearly total being indicative of mild, moderate, or major life crises with increasing probability of onset of illness (see Appendix F).

Dr. Coddington utilized the method of Holmes and Rahe (1967) modified to children, to develop his Social Readjustment Rating Ques tionnaire. Dr. Coddington described Social Readjustment as including "the amount and duration of change in a child's accustomed pattern of life resulting from various life events." As defined, social readjustment is related to the intensity and length of time necessary to accommodate to a life event, regardless of the desirability of this event. In other words, the birth of a sibling might be considered an exciting and interesting event or an unwanted event, but in either case it requires a certain amount of social readjustment.

Social event items were gathered into four lists according to age, and each event rated by teachers, pediatricians, and mental health professionals for the average degree of readjustment necessary during a particular time period (preschool, elementary school, junior high, and senior high. (Appendix F) Thus each event is assigned a value 
and rank, either or both of which may change across different age ranges. For example, in the Preschool Age Group, "Death of a Parent" is ranked \#1 with a life change unit value of 89 , the same item, in the Elementary School Age Group still ranks first, but its life change unit value increased to 91. In the Junior High School Age Group, "Death of a Parent" moves down in rank to \#2 and increases in life change unit value to 94. And finally, with the Senior High School Age Group, this event becomes \#3 in importance and the ICU value decreases to 87 .

The Coddington Social Readjustment Rating Questionnaire was administered to the parents of both the experimental and matched control children in an attempt to determine any significant differences in nature and number of life events between groups. Our experimental group had already received a diagnosis of disease, and therefore our utilization of Coddington's Social Event Rating Questionnaire was retrospective, rather than projective. As such, the Questionnaire was answered by our subjects in reference to the total life span of the identified child, rather than just the year prior to testing. The subjects were asked to fill out all sheets appropriate to the child's age during a specified period of time. The Preschool Questionnaire was answered according to events that happened to the child between age 0-5 years, the Elementary School Questionnaire answered in reference to the time period from age 5 years to the 7 th grade, Junior High was the 
start of 7 th grade, to the end of 9 th grade, Senior High was start of 10 th grade to graduation from school. We could thus obtain a total life score, in addition to the subscores from the four different age categories. The subjects were also asked to rank order the three checked items, in each category, that they as parents, felt were most important in the life of the identified child during that specified time. They also were asked to record the month and year each event occurred.

\section{CHILD'S QUESTIONNAIRE}

The present study utilized a 20 statement questionnaire developed by the researchers for administration to both the experimental and matched control children. This test has not been validated or standardized. Ten of the test items were constructed as statements relating to the child's active or passive handling of aggressive and hostile feelings which may easily arise in some general and specific situations that of ten confront most children at some time. Another ten questions were designed to assess the child's attitude toward expression of aggression and hostility in common situations. Almost all of these questions have a "good" or "right" answer, based on white, middle-class values which are fairly well known. Thus deviations from the "right" answer may not be as related to the child's attitudes as they are to other factors discussed in the analysis section. 
Test construction was accomplished by devising one set of ten questions, five of which if answered "true, "would, for the purpose of this study be seen as overt, or rather, active and direct expres sion of aggression and hostility by the child. Another five questions answered "true," would indicate a rather passive child who tended to repress or deny aggressive and/or hostile feelings. The child is termed "active" in the sense that he initiates a behavioral action as a direct response to a stimuli, or "passive" in that he initiates no behavioral action in response to the stimuli, or initiates an indirect and covert response. (Appendix E)

Another set of ten questions was designed to probe the child's attitudes toward certain types behaviors, rather than the actual behavior displayed and self-reported by the child. Five questions, if answered "Agree" would indicate a positive attitude toward active and direct (overt) expression of hostility and aggression. Another five questions answered "Agree" would indicate a positive attitude toward suppression of outward directed manifestations of aggression and hostility.

On, this questionnaire then, a predominantly passive child, who tends to repress and deny aggressive and hostile feelings, actions and attitudes, would answer the 5 passive true-false items "True," the 5 active true-false questions "False," the 5 passive agree-disagree items "Agree," and the 5 active agree-disagree items "Disagree." 
The child's questionnaire was individually administered in private by the examiner. Only those experimental and control subjects six years and older were tested. After $r$ apport had been established with the child, the procedure was to present him with a blank questionnaire, and a stack of "completed" questionnaires. The "completed" questionnaires had been arbitrarily filled in by the examiners, and then had the bottoms trimmed off $3 / 8$ of an inch, thus making them shorter than the subject's questionnaire. They were arranged out of the child's easy reach, and so that they could only be read upside down. The child was told that many children had been asked these same questions as we wanted to find out how children his age really felt about certain things. The examiner said she wanted him to tell the truth, and that he wasn't to put his name on the questionnaire. When he was done, he was to slip his in among the other children's, and then that way no one would know which one of them was his.

The questionnaire was then explained to the child and sample items demonstrated: The younger children, age 6-10, were read each statement while they marked it on their questionnaire. They were to ask questions if they didn't understand a word. The examiner sat close to the child, with her back turned toward him. The older children, age 10-15, read their own questions, with the examiner somewhere in the room in case the subject had a question. Later, the questionnaires were shuffled, and the subject's pulled out and coded. 


\section{ANALYSIS AND INTERPRETATION OF RESUITS}

\section{DESCRIPTIVE DATA}

Sibling number was controlled in the current study, but it was not possible to control the effects of birth order between the two groups of children. Table $\mathrm{V}$ presents the frequency distribution of both groups relative to birth order and sex. The majority of children, 47 percent of leukemic group and 69 percent of the control group, were classified as a youngest child. Only six total children (4 experimental, 2 control) were classified as middle children, but this finding is a result of matching procedures, as over half of the experimental group had only one sibling. Child's sex was unrelated to birth order. Approximately equal numbers of males and females were within each category for both groups.

Four of the experimental children were adopted, three were living with both adoptive parents at time of data collection, one was living with his adoptive mother, his adoptive father being deceased. As all four children were adopted at birth, adoptive parents were treated as natural parents for ease of comparison.

There was no difference in living status between the two groups (Table VI). The majority of children lived with both natural parents. 
TABLE V

FREQUENCY AND PERCENTAGE DISTRIBUTION OF BIRTH ORDER BY SEX AND GROUP

\begin{tabular}{|c|c|c|c|c|c|c|c|c|c|c|c|c|}
\hline \multirow{3}{*}{$\begin{array}{l}\text { Birth } \\
\text { Order }\end{array}$} & \multicolumn{6}{|c|}{ Experimental Group } & \multicolumn{6}{|c|}{ Control Group } \\
\hline & \multicolumn{2}{|r|}{ Males } & \multicolumn{2}{|c|}{ Females } & \multicolumn{2}{|c|}{ Totals } & \multicolumn{2}{|r|}{ Males } & \multicolumn{2}{|c|}{ Females } & \multicolumn{2}{|c|}{ Totals } \\
\hline & No. & Percent & No. & Percent & No. & Percent & No. & Percent & No. & Percent & No. & Percent \\
\hline Old est & 3 & (13) & 5 & (22) & 8 & (35) & 3 & (13) & 2 & (9) & 5 & (22) \\
\hline Middle & 2 & (8) & 2 & (9) & 4 & (18) & 1 & (4) & 1 & (4) & 2 & (9) \\
\hline Youngest & 6 & (26) & 5 & (22) & 11 & (47) & 7 & (30) & 9 & (40) & 16 & (69) \\
\hline Totals & 11 & (47) & 12 & (53) & 23 & $(100)$ & 11 & (47) & 12 & (53) & 23 & $(100)$ \\
\hline
\end{tabular}


TABIE VI

FREQUENCY AND PERCENTAGE DISTRIBUTION

OF CHILD'S LIVING ARRANGEMENT

BY GROUP

\begin{tabular}{|c|c|c|c|c|}
\hline \multirow{2}{*}{$\begin{array}{l}\text { Child's Living } \\
\text { Arrangement }\end{array}$} & \multicolumn{2}{|c|}{ Experimental Group } & \multicolumn{2}{|c|}{ Control Group } \\
\hline & Number & Percent & Number & Percent \\
\hline \multicolumn{5}{|l|}{ Both natural } \\
\hline parents & $17 *$ & (74) & 16 & $(70)$ \\
\hline Natural mother & $5 * *$ & $(22)$ & 7 & $(30)$ \\
\hline Natural father & 1 & (4) & 0 & $(0)$ \\
\hline Totals & 23 & $(100)$ & 23 & $(100)$ \\
\hline
\end{tabular}

Three children were living with both adoptive parents. **

One child lives with his adoptive mother.

Five of the experimental group, and seven of the control, lived with their natural mother, with one experimental child living with his natural father. Table VII depicts the mother's and father's marital status. Again, there was little difference between the two groups. The control group had a larger number of divorced fathers when compared to the experimental group, but this difference may be due to the two "unknowns" in the Experimental group who, while they are divorced, are not classified as such. 
TABLE VII

FREQUENCY AND PERCENTAGE DISTRIBUTION OF MARITAI STATUS BY PARENT AND GROUP

\begin{tabular}{|c|c|c|c|c|c|c|c|c|}
\hline \multirow[b]{3}{*}{ Marital Status } & \multicolumn{4}{|c|}{ Experimental Group } & \multicolumn{4}{|c|}{ Control Group } \\
\hline & \multicolumn{2}{|c|}{ Father's } & \multicolumn{2}{|c|}{ Mother's } & \multicolumn{2}{|c|}{ Father's } & \multicolumn{2}{|c|}{ Mother's } \\
\hline & No. & Percent & No. & Percent & No. & Percent & No. & Percent \\
\hline Married & 17 & (74) & 17 & (74) & 16 & (70) & 16 & (70) \\
\hline Divorced & 1 & (4) & 4 & (18) & 5 & (22) & 5 & (22) \\
\hline Remarried & 2 & (9) & 1 & (4) & 1 & (4) & 1 & (4) \\
\hline Deceased & 1 & (4) & 0 & (0) & 1 & (4) & 0 & (0) \\
\hline Widowed & 0 & (0) & $1:$ & (4) & 0 & (0) & 1 & (4) \\
\hline Unknown & 2 & (9) & 0 & (0) & 0 & (0) & 0 & (0) \\
\hline Totals & 23 & $(100)$ & 23 & $(100)$ & 23 & $(100)$ & 23 & $(100)$ \\
\hline
\end{tabular}


Table VIII reports the frequency distribution of parents into working, non-working, and student categories. The classification of six male subjects, two experimental fathers and four control, were unknown, as the mother's did not know how to contact them. A slight majority of the control mothers were working as compared to the experimental mothers, which may be influenced by the greater majority of working mothers in the preschool sample population. Slightly more experimental fathers than control father s were working, however, there were four control fathers who were not classified which may account for the between group difference.

Ages of experimental mothers ranged from 25-56 years with a mean age of 36 years, while control mothers were from 24-51 years with a mean of 37 years. Experimental fathers ranged from 24-55 with a mean of 37 , and control fathers were 27-49 years with a mean of 36 years (Table IX). The majority of subjects in all four groupings were between 30-40. The experimental parents were slightly older than the controls as expressed in the group means. The age mean for the leukemic mothers was 3 points higher than the control mothers, and the leukemic mothers had a higher frequency of ages over 40 than the control mothers (6 and 3 respectively). This difference is maximized for the mothers in the 50-60 age ranges, where the leukemic group has a frequency of 4 compared to the control of 1 . Analysis of the frequency distribution of fathers ages over 50 reveals a similar 


\section{TABLE VIII}

FREQUENCY AND PERCENTAGE DISTRIBUTION

OF EMPLOYMENT STATUS BY PARENT

\section{AND GROUP}

\begin{tabular}{|c|c|c|c|c|c|c|c|c|}
\hline & \multicolumn{4}{|c|}{ Experimental Group } & \multicolumn{4}{|c|}{ Control Group } \\
\hline & \multicolumn{2}{|c|}{ Father's } & \multicolumn{2}{|c|}{ Mother's } & \multicolumn{2}{|c|}{ Father's } & \multicolumn{2}{|c|}{ Mother's } \\
\hline Status & No. & Percent & No. & Percent & No. & Percent & No. & Percent \\
\hline Working & 19 & $(82)$ & 5 & $(22)$ & 16 & (69) & 8 & (35) \\
\hline Non-working & 2 & (9) & 16 & (69) & 1 & (4) & 12 & $(52)$ \\
\hline Student & 0 & (0) & 2 & (9) & 2 & (9) & 3 & (13) \\
\hline Unknown & 2 & (9) & 0 & $(0)$ & 4 & (18) & 0 & (0) \\
\hline
\end{tabular}




\section{TABLE IX}

FREQUENCY AND PERCENTAGE DISTRIBUTION OF

PARENT'S AGE BY GROUP WITH MEANS

\begin{tabular}{|c|c|c|c|c|c|c|c|c|}
\hline \multirow[b]{3}{*}{ Parent's Age } & \multicolumn{4}{|c|}{ Experimental Group } & \multicolumn{4}{|c|}{ Control Group } \\
\hline & \multicolumn{2}{|c|}{ Mother's } & \multicolumn{2}{|c|}{ Father's } & \multicolumn{2}{|c|}{ Mother's } & \multicolumn{2}{|c|}{ Father's } \\
\hline & No. & Percent & No. & Percent & No. & Percent & No. & Percent \\
\hline $20-24$ & 0 & (0) & 1 & (4) & 2 & (9) & 0 & (0) \\
\hline $25-29$ & 6 & (26) & 3 & (13) & 6 & (26) & 3 & (13) \\
\hline $30-34$ & 9 & $(40)$ & 6 & (26) & 5 & (22) & 6 & (26) \\
\hline $35-39$ & 2 & (9) & 6 & (26) & 7 & (30) & 8 & (35) \\
\hline $40-44$ & 1 & (4) & 0 & $(0)$ & 2 & (9) & 0 & (0) \\
\hline $45-49$ & 1 & (4) & 1 & (4) & 0 & $(0)$ & 4 & (17) \\
\hline $50-54$ & 3 & (13) & 3 & (13) & 1 & (4) & 0 & (0) \\
\hline $55-60$ & 1 & (4) & 1 & (4) & 0 & (0) & 0 & (0) \\
\hline Unknown & $\underline{0}$ & (0) & 2 & (9) & 0 & (0) & 2 & (9) \\
\hline Totals & 23 & $(100)$ & 23 & $(100)$ & 23 & $(100)$ & 23 & $(100)$ \\
\hline Means & \multicolumn{2}{|c|}{36} & \multicolumn{2}{|c|}{37} & \multicolumn{2}{|c|}{33} & \multicolumn{2}{|c|}{36} \\
\hline
\end{tabular}


tendency, with 4 experimental fathers in the 50-60 age range, as compared with none in the control fathers group.

In summary, it may be said that comparisons between the experimental and control groups yielded few differences based on des criptive data alone. The groups are seen as fairly similar with respect to marital status, child's living arrangements, parent's work, and birth order of child. One of the most interesting items was not really a difference between the two groups, but was the finding that 47 percent of the leukemic children were a youngest child. This find ing is in opposition to that reported by Greene and Miller (1958) in a review of the literature, that a majority of leukemic children are firstborns.

There was some difference between the two groups in mean ages. The experimental groups were characteristically older, and were 'further differentiated by a greater number of subjects in the 50-60 age range as compared to the controls.

\section{CHILD'S QUESTIONNAIRE}

Data on this measure was gathered from 17 matched pairs of children, 6 years old, for a total of 34 children distributed into two groups. Subject's answers on the first ten questions were assigned to the True or False category, and the resulting classifications summed for both groups: Answers on the second set of ten questions were 
assigned to the Agree or Disagree category, and the resulting classifications summed for both groups.

Tables $X, a$ and $b$, are an item analyses of experimental and control children's responses on the Child's Questionnaire, and the with-in group and between group differences.

Both groups of children display a wide range of with-in group variability of response on most questions, indicating little agreement on test items. The between group differences in item response are also not significant.

Predictions had been made regarding the manner in which both groups of children would respond on each question; the normal controls, attitudes and behaviors would reveal an active and direct (overt) response to aggressive and hostile feelings, while the leukemic group would reveal a more passive and indirect (covert) response, reflec3 tive of a possible tendency to repress and deny such feelings. The difference score for each group on all questions was coded A (active) $P$ (passive), according to which direction the majority of each group responded (Appendix E). On the majority of the questions, both groups responded in the same direction, therefore no significant difference between groups was found.

In summary, there was not a significant difference between the two groups on answering patterns for the child's questionnaire, disproving hypotheses four. 


\section{TABLE Xa}

ITEM ANALYSIS OF TRUE-FALSE RESPONSES ON CHILD'S QUESTIONNAIRE,

PART I SHOWING ACTIVE-PASSIVE CODE WITH-IN GROUP AND BETWEEN GROUP VARIANCE

\begin{tabular}{|c|c|c|c|c|c|c|c|c|c|}
\hline \multirow[b]{2}{*}{ No. } & \multicolumn{4}{|c|}{ Experimental Group } & & \multicolumn{4}{|c|}{ Control Group } \\
\hline & $\begin{array}{c}(+) \\
\text { True }\end{array}$ & $\begin{array}{c}(-) \\
\text { False }\end{array}$ & $\begin{array}{l}\text { Within } \\
\text { Group } \\
\text { Variation }\end{array}$ & $\begin{array}{c}\text { Active } \\
\text { or } \\
\text { Passive }\end{array}$ & True & False & $\begin{array}{l}\text { Within } \\
\text { Group } \\
\text { Variation }\end{array}$ & $\begin{array}{l}\text { Active } \\
\text { or } \\
\text { Passive }\end{array}$ & $\begin{array}{l}\text { Between } \\
\text { Group } \\
\text { Variation }\end{array}$ \\
\hline 1 & 7 & 10 & -3 & $\mathbf{A}$ & 9 & 8 & +1 & $\mathbf{P}$ & 4 \\
\hline 2 & 2 & 15 & -13 & $\mathbf{P}$ & 6 & 11 & -5 & $\mathbf{P}$ & 8 \\
\hline 3 & 8 & 9 & -1 & $\mathbf{A}$ & 4 & 13 & -9 & $\mathbf{A}$ & 8 \\
\hline 4 & 8 & 9 & -1 & $\mathbf{A}$ & 7 & 10 & -3 & $\mathbf{P}$ & 2 \\
\hline 5 & 11 & 6 & +5 & $\mathbf{P}$ & 8 & 9 & -1 & $\mathbf{A}$ & 6 \\
\hline 6 & 11 & 6 & +5 & $\mathbf{P}$ & 10 & 7 & +3 & $\mathbf{P}$ & 2 \\
\hline 7 & 8 & 9 & -1 & $\mathbf{P}$ & 7 & 10 & -3 & $\mathbf{P}$ & 2 \\
\hline 8 & 3 & 14 & -11 & $\mathbf{A}$ & 5 & 12 & -7 & $\mathbf{A}$ & 4 \\
\hline 9 & 4 & 13 & -9 & $\mathbf{P}$ & 5 & 12 & -7 & $\mathbf{P}$ & 2 \\
\hline 10 & 4 & 13 & -9 & $\mathbf{P}$ & 6 & 11 & -5 & $\mathbf{P}$ & 4 \\
\hline
\end{tabular}


TABLE X $\mathbf{b}$

ITEM ANALYSIS OF AGREE-DISAGREE RESPONSES ON CHILD'S QUESTIONNAIRE, PART II SHOWING ACTIVE-PASSIVE CODE, WITH -IN GROUP AND BETWEEN. GROUP VARIANCE

\begin{tabular}{|c|c|c|c|c|c|c|c|c|c|}
\hline \multirow[b]{2}{*}{ No. } & \multicolumn{4}{|c|}{ Experimental Group } & \multicolumn{5}{|c|}{ Control Group } \\
\hline & Agree & Disagree & $\begin{array}{l}\text { Within } \\
\text { Group } \\
\text { Variation }\end{array}$ & $\begin{array}{l}\text { Passive } \\
\text { or } \\
\text { Active }\end{array}$ & Agree & Disagree & $\begin{array}{l}\text { Within } \\
\text { Group } \\
\text { Variation }\end{array}$ & $\begin{array}{l}\text { Active } \\
\text { or } \\
\text { Passive }\end{array}$ & $\begin{array}{l}\text { Between } \\
\text { Group } \\
\text { Variation }\end{array}$ \\
\hline 1 & 4 & 13 & -9 & $\mathbf{P}$ & 8 & 9 & -1 & $\mathbf{A}$ & 8 \\
\hline 2 & 6 & 11 & -5 & $\mathbf{A}$ & 6 & 11 & -5 & $\mathbf{P}$ & 0 \\
\hline 3 & 10 & 7 & +3 & $\mathbf{P}$ & 11 & 6 & +5 & $\mathbf{P}$ & 2 \\
\hline 4 & 2 & 15 & -13 & $\mathbf{P}$ & 3 & 14 & -11 & $\mathbf{P}$ & 2 \\
\hline 5 & 13 & 4 & +9 & $\mathbf{P}$ & 12 & 5 & +7 & $\mathbf{P}$ & 2 \\
\hline 6 & 5 & 12 & -7 & $\mathbf{P}$ & 3 & 14 & -11 & $\mathbf{A}$ & 4 \\
\hline 7 : & 16 & 1 & +15 & $\mathbf{P}$ & 15 & 2 & +13 & $\mathbf{A}$ & 2 \\
\hline 8 & 9 & 8 & +1 & $\mathbf{P}$ & 12 & 5 & +7 & $\mathbf{P}$ & 6 \\
\hline 9 & 0 & 17 & -17 & $\mathbf{P}$ & 3 & 14 & -11 & $\mathbf{P}$ & 6 \\
\hline 10 & 8 & 9 & -1 & $\mathbf{P}$ & 8 & 9 & -1 & $\mathbf{P}$ & 0 \\
\hline
\end{tabular}




\section{SOCIAI EVENT RATING QUESTIONNAIRE}

Data on this measure consisted of a tolul life event score for 22 experimental children and 23 control children with from one to four additional sub-category scores reflecting age categorization of the child. The older the child, the more categories he would potentially fill. The purpose was to quantify the significance of life events as they occurred within and between our two groups of children.

Our utilization and analysis of this measure was somewhat different than that originally intended by Dr. Coddington. Instead of completing only the age-range sheet appropriate to the subject's age relative to the events of the preceding year, our parents completed all relevant sheets for the child, checking all items occurring in the life of the child for the time span represented on each sheet. Parents twere also asked to rank the three most important variables for each sheet and put the approximated date beside it. In this way we hoped to get a more total picture of each child's total life and the nature and frequency of specified events occurring.

Scores were tabulated by assigning Coddington's life change unit values (Appendix F) to each event checked by the parent for the child. These values, for each of the one to four age-range sheets, were summed, yielding a total life change unit value score for each time period. All relevant subtotal scores were then summed, yielding a 
grand or overall total. While all children had a total score, the number of subtotal scores depended upon each child's current age. Most children were around eight years old and thus returned the Preschool age and Elementary School age sheets. The Elementary School age sheet includes the time period from six years of age to the end of sixth grade, and so item frequency and total scores are heavily influenced by age. This effect makes within group discussion of scores unreliable. Appendix F presents the item analysis of all events for both groups.

Between group comparisons of matched pairs is possible, and was used to test Hypothesis two; the experimental group will achieve higher scores on this measure than matched controls. Comparison was made only on total scores. Preliminary analysis revealed that among our 22 matched pairs, only 11 of the experimental children had ! higher total scores than their controls. Our second hypothesis is thus disproved. Appendix $G$ presents the table of matched total scores. The frequency of group reports on "object loss" events may be found in Appendix H. There was not a significant difference between the leukemic and normal groups in total number, or type of events, reported. Our third Hypothesis, that there will be a significant difference between groups in reporting of object loss, with the leukemic group reporting a greater number of events, was not supported. 
It thus appears that the number and type of social events occurring within the life of the child are not sufficient to differentiate the two groups. The observed similarity between the true groups may be a valid finding, but may also be the result of extraneous factors combining to produce a leveling effect. A number of events for the leukemic group, known from medical records and other sources, were not reported on some of the Social Event Questionnaires. Under reporting possibly occurred within the control group also, but its known occurrence within the leukemic group may suggest a higher degree of defensiveness for the experimental group. Differences in reporting may also be related to accuracy of completion, as it was noted that a few parents did not understand some of the items, mistakes were made in assigning events to the appropriate age-range sheet, some people checked but did not rank and date items, and so on. These ! differences in reporting affected results, but it is not known to what degree.

IV. MINNESOTA MULTIPHASIC PERSONALITY INVENTORY

The Minnesota Multiphasic Personality Inventory was self-administered and hand scored by one of the researchers. Raw scores on all of the clinical scales $(1-10)$, corrected for $K$, plus two of the validity scales $(F, K)$ were used in comparing the two groups of parents. 
There was no preconceived idea as to what scales might differentiate the experimental and control groups. All 23 sets of parents were asked to complete the test. Complete data on both parents was available for 13 of the experimental families and 15 of the control families.

The statistical method used was a Stepwise Discriminant Analysis. By this method, sets of response variables are examined to find the best linear combination of variables that provides the maximum discrimination between groups (Dixon, 1965).

Table XI depicts those ten variables that were found to provide the maximum discrimination between the leukemic experimental and normal control groups. The first five variables, in combination, had a high level of significance $(p<.005)$. With these five variables alone, it is possible to classify all 13 parents with leukemic children and 14 out of 15 parents with normal children into their appropriate group. By the time the tenth variables is entered all subjects are correctly classified.

The first variable, father's Si score (social introvert-extrovert) by itself is sufficient to differentiate a majority of the subjects correctly. The addition of variable number two, mother's D score (depression), in combination with the first variable, further increases the ability to define groups.

It is clearly evident that certain MMPI scale scores, alone or in combination, are significantly capable of identifying which subjects 
TAB LE XI

STEPWISE DISCRIMINATE ANALYSIS OF TEN VARIABLES; MEANS, STANDARD

DEVIATIONS BY GROUP; GRAND MEANS, F VAIUES, DEGREES

OF FREEDOM, P VALUES

\begin{tabular}{|c|c|c|c|c|c|c|c|c|}
\hline \multirow{2}{*}{$\begin{array}{l}\text { MMPI } \\
\text { Variable }\end{array}$} & \multicolumn{2}{|c|}{$\begin{array}{l}\text { Experimental } \\
\text { Group }\end{array}$} & \multicolumn{2}{|c|}{$\begin{array}{l}\text { Control } \\
\text { Group }\end{array}$} & \multirow{2}{*}{$\begin{array}{l}\text { Grand } \\
\text { Means }\end{array}$} & \multirow[b]{2}{*}{ F Values } & \multirow{2}{*}{$\begin{array}{l}\text { Degrees of } \\
\text { Freedom } \\
n_{1} / n_{2}\end{array}$} & \multirow[t]{2}{*}{$\mathbf{P}<$} \\
\hline & $\mathbf{M}$ & SD & $\mathbf{M}$ & SD & & & & \\
\hline \multicolumn{9}{|l|}{ Father's Scale 0} \\
\hline Mother's Scale 1 & 33.00 & 10.95 & 24.20 & 1.15 & 28.28 & 6.50 & $1 /<0$ & 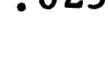 \\
\hline (Hypochondriasis) & 15.46 & 4.55 & 17.00 & 6.72 & 16.28 & 5.03 & $2 / 25$ & .025 \\
\hline Father's Scale 9 & & & & & & & & \\
\hline (Hypomania) & 18.46 & 4.42 & 18.73 & 5.39 & 18.60 & 4.94 & $3 / 24$ & .025 \\
\hline $\begin{array}{l}\text { Father's F Score } \\
\text { Father's Scale } 3\end{array}$ & 3.92 & 2.98 & 5.06 & 4.16 & 4.53 & 8.30 & $4 / 23$ & .005 \\
\hline (Hysteria) & 19.69 & 4.00 & 19.93 & 3.36 & 19.82 & 12.41 & $5 / 22$ & .005 \\
\hline $\begin{array}{r}\text { Father's Scale } 7 \\
\text { (Psychasthenia) }\end{array}$ & $25-23$ & 3,49 & 2340 & 503 & 2425 & 1226 & $6 / 21$ & 005 \\
\hline Father's Scale 4 & & & & 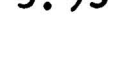 & & & & \\
\hline (Psychopathic Deviate) & 21.69 & 4.97 & 22.73 & 4.43 & 22.25 & 12.77 & $7 / 20$ & .005 \\
\hline $\begin{array}{c}\text { Father's Scale } 2 \\
\text { (Depression) }\end{array}$ & 20.84 & 5.27 & 18.60 & 3.75 & 19.64 & 13.56 & $8 / 19$ & .005 \\
\hline $\begin{array}{l}\text { (Paranoid) } \\
\text { Mother's Scale } 2\end{array}$ & 9.15 & 3.73 & 9 & 1.96 & 9.07 & 14.55 & $9 / 18$ & .005 \\
\hline (Depression) & 24.00 & 4.74 & 22.93 & 7.42 & 23.42 & 17.69 & $10 / 17$ & .005 \\
\hline
\end{tabular}


are likely to be parents of leukemia children. The most differentiating variable, Father's Social Introvert-Extrovert (Si) scale score, reveals that fathers with leukemic children have a higher mean scale score than the control group. (Interpretations based on the MMPI Codebook for Counselors, Drake and Oetting, 1959). This score is somewhat above the normal response range ( $T$ score of 45-55) on the MMPI, while the controls mean score is well within the normal range. This scale measures the tendency to withdraw from social contacts. High scores would tend toward introversion and shyness, displaying a relative lack of interpersonal social skills and engaging in few group activities.

The second variable, Mother's Hypochondriasis (Hs) scale score further differentiates the two groups in combination with Father's (Si) scale score. Mothers of leukemia children as a group, : tended to score lower on this scale than the mothers of healthy children. Low Hs scores often indicate infrequent use of physical symptoms as a defensive response to stress, utilizing other kinds of behavior.

The third variable in the discriminant function was Father's Hypomania (Ma) scale score, with both group mean scores rather low. These scores, while very similar between the two groups (experimental group slightly less variable), must be viewed with respect to 
their weighted values with the previous variables. Moderately low Ma scores often indicate someone who seeks reassurance and may be somewhat dependent. They lack expressive outlets, and so, are unable to decrease anxiety by outward directed action.

For the experimental fathers, as differentiated from the control fathers, these traits must be thought of in conjunction with their additional tendency towards introversion and isolation.

The fathers of leukemic children had lower normal scale scores with less variability, than the control fathers on the F Scale. This is one of the validity scales, indicating test taking attitudes, the lower scores of the experimental fathers denotes better comprehension of items and more care in answering. A somewhat peripheral aspect of the $F$ score is its relationship with the $K$ Score. $F$ minus $K$ values for both groups were -11. These high negative values often suggest ! defensiveness and a tendency to appear calm in spite of inner anxiety. Variable five is father's Hysteria (Hy) scale scores. While mean scores and variability are almost identical between groups, this variable in conjunction with the previous four, seems to maximize the discrimination between ofather s with leukemic children and those with normal children.

In partial summary, it is clear that the correlation of five MMPI scale scores of both parents, of a leukemic child, evidence a remarkable ability to discriminate parents with leukemic children 
from those with normal children $(p<.005)$. The addition of the next five variables further refines the discriminant power $(p<.005)$.

Our first hypothesis, that parents of leukemic children will significantly differ on the MMPI scale scores from the normal control parents, is thus supported.

Interpretation of the results seems to suggest that, of a group of parents with either normal or leukemic children, a husband with an MMPI Si score of $33 \pm 11$, Ma score of $18 \pm 4, F$ score of $4 \pm 3$ and Hy score of $19 \pm 4$, who is married to a woman with an Hs score of $15 \pm 4$, will most likely have a child with leukemia. This possibility increases if the father's $\mathrm{Pt}, \mathrm{Pd}, \mathrm{D}$, and $\mathrm{Pa}$ scores and the mother's D score, fall within the limits of the scores in Table XI.

Additional understanding of the mother and father of the leukemic child is possible when the mean scale scores, for all scales, are Examined according to their inter relationships (Appendix I). Interpretations of these scale score relationships are based upon descriptions presented in the MMPI Cod ebook for Counselors by Drake and Oetting, 1959.

There were four ind ependent variables that had a level of significance. They are as follows: Father's Si scale score $(p<.025)$, Father's D scale score $(p<.250)$, Mother's Ma scale score $(p<.250)$ and Mother's Si scale score $(p<.250)$. 
Examination of the pattern of high and low mean scale scores of the mother 8 and fathers with leukemic children revealed a number of possible interesting personality characteristics, which must remain theor etical until further validation by clinical observation and replication is possible.

Scales $\mathrm{Si}+$, Dt and Pt+ coded high suggests experimental fathers might display a fairly serious and extensive lack of social skills, a tendency toward introversion and feelings of inferiority. They may be depressed and indecisive, have difficulty adjusting socially and have a mother conflict. Ptt coded high suggests this pattern is probably not just a reflection of a specific problem related to some aspect of the immediate environment, but rather denotes a more generalized emotional problem.

The additional Mft and Hyt scores reveals that fathers of leukemic children might tend to control their expression of aggressive or non-conforming behavior. In relationships, they would lack aggressiveness and tend to be dependent. Mft in combination with $\mathrm{D}+$ and Ptt indicates fathers possibly tend to worry excessively, may have insomnia, and might have conflicts in their home life.

A low $\mathrm{Ma}-$, relative to the other scores, implies that leukemic father $s$ could tend to be dependent with a relative lack of drive and need reassurance. A low $\mathrm{Ma}$ - indicates that characteristic behavior usually associated with a person's high scores are often not overtly 
exhibited. Thus fathers of leukemic children might tend to disguise or hide many of their difficulties.

The high Sit, Dt and Pt+ mean scores of mothers of leukemic children suggests characteristics similar to the fathers. They might tend to be socially shy, lack self-confidence, have trouble relating to the opposite sex, and have generalized feelings of insecurity, often over some physical feature. Their low Ma-score would act to intensify these characteristics. The additional presence of high Sct indicated the possibility of a more serious general disturbance, and tends to emphasize characteristics suggested by high scores.

A low Mf-, in combination with the above implies the mothers might have problems dealing with anxiety. Mf-also tends to intensify the effects of high scores. Low Mf- with D+ and Pdt reveals a possible mother conflict.

A low Hs - tends to intensify possible problems suggested by high scores and also suggests that mothers might have generalized rather than specific defenses against anxiety. This low score in conjunction with Mf- and $\mathrm{Ptt}$, implies these mothers may have some conflict relating to their home life, that they are relatively non-responsive and have poor rapport with others.

In summary, the analysis of MMPI mean scores suggest that parents of leukemịc children may have many similar personality 
characteristics, with the fathers evidencing a greater ability to control and disguise their feelings and behaviors. 


\section{DISCUSSION}

The current paper was an attempt to validate and extend as pects of prior cancer and personality studies, and determine the interdependence of a number of variables in reference to the development of malignancy in childhood. The study incorporated some additional improvements in design to control some of the many extraneous effects influencing results in psychosomatic research. The influence of immunity or host resistance in the ontogenesis of disease (Blumberg, et al. 1954) and subsequent differential response patterns (Bendien and Groen, 1963), is becoming increasingly recognized and investigated.

$\therefore \quad$ Separation experiences and object losses of the patient are often described as important precursers in development of cancer (Greene, 1966) and other diseases (Holmes, 1968). Analysis of the quantity and quality of a child's life events revealed no differences between the leukemic and normal children. Events defined as "object loss" occurred with equal frequency in both groups. However the validity of these findings is questionable, and more rigorous investigations with smaller and more precise time intervals are needed. 
Other authors, such as Bahnson (1969) have suggested it is the child's idiosyncratic response to an event, rather than the event per se, which is the determining factor in susceptibility to illness. The present study attempted to access a potential variance of response between two groups of children, but results were inconclusive due to the internal weakness of the measure, strong cultural effects, and perhaps the inappropriateness of the variable chosen. More definitive methods of child assessment have a great potential use in the identification and description of some possibly unique characteristics of these children.

An assumption was made that the parents of a child, are as pects of that child's environment and as such may be regarded as stimulus factors to which the child must respond and adapt. One method of dealing with environmental stimuli is to familiarize oneself with the object or event, and learn how to most effectively respond in relation to the object to minimize threat of danger or the unknown. One learns how to react appropriately. Therefore, to better understand the child, one must understand the parents; those characteristics they reveal which determine the child's response.

Preliminary analysis of parental characteristics as measured by the MMPI significantly supports the contention that the rather unique response of the leukemic child to his environment, i. e. dis ease, is reflected by a set of characteristic differences displayed by 
his parents when compared with normal children's parents.

A problem of interpretation arises, however, when it is asked whether these parental characteristics, as determined from MMPI scores, are a relatively stable aspect of the parent's personalities, or are a response to a recent change resulting from their child's illness. It is quite probable that both factors operate simultaneously, with the parent's MMPI scores reflecting both factors to some extent.

In this study, the major purpose was simply to demonstrate that there are quantifiable differences between two defined populations. The next objective was to identify and describe any significant findings. It is only with extreme caution that results can be discussed in relation to their effect on the disease process. Parental personality characteristics, as interpreted from MMPI scores, can be viewed $\therefore$ in several different ways, all of which provide implications for treatment.

If these parental personality characteristics are interpreted as a reaction to the stress of having a child diagnosed leukemic, an understanding of their normal pattern of response, and coping mechanisms is gained. This knowledge would be helpful for the clinician attempting to understand the adjustment patterns of these parents. The clinician would know what type of response to expect from a parent with a dying child; a response which ordinarily might not be evident 
from their overt behaviors. With this knowledge, he could make a faster assessment of problem areas where intervention is indicated, when intervention is appropriate and an assessment of the best method enhancing treatment results.

If the child's disease is causing parents to respond in a manner implied by test results, and this response is different from that prior to a diagnosis, a question arises regarding how the child, in turn, may respond to this change in the parents. If this change in the parents, confuses and negatively affects the child, efforts should be directed toward minimizing its impact on the child, or helping the parents cope in a more positive manner.

An alternate interpretation of MMPI personality characteristics of the parents is that, although some of the scales are highly variable with current mood, many are more stable and will tend to suggest with some typical attributes of the parents characteristics prior to diagnosis. Schofield (1956) and Gallagher (1956), in separate studies of MMPI score changes following therapy, reported that some scales seem to be very stable. These scales were Ma, Mf, Hy, Pd and $\mathrm{K}$. Investigating illness effects on test scores, Bahnson and Bahnson (1969), reported that comparisons of test scale scores between cancer patients, normal controls, coronary and other seriously ill patients, resulted in identification of the cancer group as different 
from the other groups. He concludes that the differences found in the cancer group were not a result of the illness alone.

In their MMPI Codebook, Drake and Oetting (1959) present patterns of scale scores that are usually regarded as indicative of a deeper, more serious, and generalized emotional reaction, as opposed to a more specific and transient response to a situational conflict. The parents of leukemic children revealed a pattern suggesting a generalized, rather than a specific reaction.

There are thus some indications that typical and stable personality characteristics, or ways of reacting to stimuli, may be expressed in MMPI scale scores. This implies the possibility that some of the suggested personality characteristics of experimental parents may denote standard methods of dealing with their environment. This interpretation of the study's results would mean that predictions of a child's susceptibility to the disease may be possible by examining his parent's MMPI profiles. This knowledge could potentially be utilized for early identification of high risk subjects and for defining areas of preventative treatment.

An implication of the study was the rather unexpected finding that the leukemic and control groups were differentiated by the dis criminant analysis primarily through' the father's MMPI scores. With a few exceptions (Greene, 1966), the bulk of the literature is directed toward describing and interpreting the mother-child 
relationship of the cancer patient, with little discussion of the father's role. The present study seems to imply that the father's characteristics are highly significant and reveal a need for additional studies describing the nature of the father-child relationship.

The present research also seemed to suggest some interesting similarities between the personality characteristics of parents of leukemic children, and personality characteristics of cancer patients, reported in the literature in the Introduction.

A number of observations regarding cancer patient's personalities seem directly applicable to the current findings. Cancer patients have been described both prior and subsequent to diagnosis, as being unable to maintain satisfactory relationships, with a tendency to turn inward, easily giving up emotionally reacting with people, able to maintain outwardly appropriate relationships, not showing behavioral regression under stress (Bahnson, 1966, 1969); having feelings of hopelessness (Greene, 1966); experiencing loneliness, guilt and self-condemnation, yet are able to carry out usual responsibilities (LeShan, 1966); presence of unresolved feelings and a disturbed relationship with a parent (Solomon, 1969). These observations seem to describe many characteristics of the leukemic child's parents, especially the father, as were interpreted from the MMPI scores. Bozeman, et al. (1955) noted that mothers of leukemic 
children may have a disturbed relationship with their own mothers, a possibility that is also suggested by our own findings.

It was also noted that the leukemic parent's mean scores corresponded to all of the profile characteristics Blumberg (1954) found assooiated with patients with rapidly progressing cancers. High negative F-K scores, D scores of 55 and above, elevated higher than Hs and Hy, and low Ma scores, were revealed by the group means of fathers with leukemic children. Leukemic mothers also had a high negative F-K score, and had an Ma score much lower than the fathers.

The similarity of some personality characteristics describing adult cancer patients, and those suggested for the leukemic child's parents, are highly intriguing. This similarity, when viewed relative to the nature and quality of the leukemic child-parent relationship, suggests many interesting areas for research. Bennette (1969) offers a number of provoking theoretical considerations, useful in understanding the interactive adaptive responses between parent and child. Numerous interpretations regarding the meaning of these relationships are possible, but are beyond the limits of this study. 


\section{SUMMARY}

$\checkmark$

Comparisons on three quantifiable measurements have been made between experimental leukemic families and normal control families.

There was not a distinct difference between the two groups in reporting of total number of significant social events for the matched pairs of children. The number of items coded as "object loss" was similar for both groups.

There was also no evidence supporting the predictions that the leukemic children would show more agreement on questions, and tend to answer in the passive coded direction.

- A combination of five parental MMPI scale scores was found to be significant at the .005 level. These scales were father's Si, Ma, F, Hy and mother's Hs.

These five variables provided maximum discrimination between the two groups; classifying all experimental parental pairs and all but one of the control parent pairs, into the correct group.

Scale scores of fathers proved to be the best discriminators between groups of children. The first variable entered, father's $\mathrm{Si}$ score, had a high level of significance $(.025)$. The higher mean score 
for fathers of leukemic children suggest they're characterized by introversion, shyness, relative lack of social activities, poor social relationships and difficulty adjusting socially.

Leukemic parents seemed to display rather similar group MMPI profiles. Scale scores assessment suggested difficult social adjustment, introversion, feelings of inferiority, diffuse anxiety, mother or home conflict, and generalized emotional problems $r$ ather than specific situational response. Additionally, it seemed that the fathers of leukemic children might tend to inhibit and control the expression of emotional feelings. 


\section{IMPLICATIONS FOR TREATMENT AND RESEARCH}

The ultimate benefit to be derived from any psychosocial study of disease is the extent to which results enhance our knowledge about the patient and his unique response to disease. It is increasingly clear that factors other than medical treatment affect the expression of the disease process (Bahnson, 1966a). Psychosocial factors should be evaluated in conjunction with any therapeutic treatment as part of a comprehensive and integrated approach. Treatment may be viewed as an attempt to increase the adaptive capacity of the patient, and facilitate recovery,

Specially trained social workers, psychologists and other mental health workers can help the patient communicate his problems and conflicts, and by encouraging ventilation of emotions, assist in reducing anxiety and fears which are retarding recovery (Bahnson, 1969).

Clinicians who are aware of the patient's underlying feelings, probable mechanisms of reaction and defense, and the quality of his relationships, can effect a more powerful and precise intervention when needed, or carefully refrain when contraindicated. Psychosocial factors pertaining to relapses and those contributing to 
sustained remission, need to be examined for clues as to how to improve functioning and prognosis of the cancer patient.

Another potential benefit of psychosomatic studies is the identification of the configuration of variables most likely to produce increased susceptibility to disease. Hopefully, this knowledge will furnish some predictive power enabling the early identification of cancer-prone individuals and appropriate initiation of intervention techniques.

Research techniques must be refined and there is a need for replication and follow up studies. Investigation of childhood malignancies is a relatively new area subject to many methodological difficulties. Childhood cancer should be examined for its similarities and differences with respect to cancer in adults and other childhood diseases. While this study suggests significant personality differences between parents of leukemic and normal children, the precise nature of these differences, their interpersonal expression in relationships, effect upon the maturing child, variability over time, etc., merit further attention. While most child studies deal with motherchild relationships, our results with fathers delineate a need for a new approach. 


\section{BIBLIOGRAPHY}

Alexander, Franz G. and Selesnik, Sheldon T. 1966. The History of Psychiatry. New York: Harper Row. 388.

Ariel, I. M., and G. T. Pack. 1960."Cancer in Infancy and Child . hood, "New York Journal of Medicine. LX, 409.

Bahnson, Claus Bahne. 1966. "Panel Discussion: Retrospects and Prospects," Annals of the New York Academy of Sciences, CXXV, Art. 3, $1028-1055$.

Bahnson, Claus, and Marjorie Bahnson. 1966. "Role of the Ego Defenses: Denial and Repression in the Etiology of Malignant Neoplas m, "Annals of the New York Academy of Sciences, CXXV, Art. 3, 827-846.

Bahnson, Claus Bahne. 1969. "Theoretical Psychophysiological Considerations: General Discussion," Annals of the New York Academy of Sciences, CLXIV, Art. 2, 590-611.

Bahnson, Marjorie and Claus Bahne Bahnson. 1969. "Ego Defenses $\therefore$ in Cancer Patients," Annals of the New York Academy of Sciences, CLXIV, Act. 2, 546-560.

Bard, Morton. 1966. "Clues to the Psychological Management of Patients with Cancer," Annals of the New York Academy of Sciences, CXXV, Art. 3, 995-1000.

Bendien, J. and J. Groen. 1963. "A Psychological-Statistical Study of Neuroticism and Extraversion in Patients with Myocardial Infarction," Journal of Psychosomatic Research, VII, 11-15.

Bennette, Graham. 1969. "Psychic and Cellular Aspects of Isolation and Identity Impairment in Cancer: A Dialectic of Alienation," Annals of the New York Academy of Sciences, CIXIV, Art. 2, 352-365. 
Blumberg, Eugene M., Philip M. West, and Frank W. Ellis. 1954. A Possible Relationship Between Psychological Factors and Human Cancer," Psychosomatic Medicine, XVI, No. 4.

Bozeman, M. E. , C. E. Obrach, and A. M. Sutherland. 1955. "Psychological Impact of Cancer and its Treatment: III. The Adaptation of Mothers to the Threatened Loss of Children Through Leukemia: Part I," Cancer. VIII, 1.

Booth, Gotthard. 1969. "General and Organ-Specific Object Relationships in Cancer, "Annals of the New York Academy of Sciences," CIXIV, Art. 2, 568-578.

Brown, Fred. 1966. "The Relationship Between Cancer and Personality," Annals of the New York Academy of Sciences, CXXV, Art. $3,865-874$.

Callaway, E. 1952. "The Psychological Care of the Cancer Patient," Journal of the Medical Association of Georgia, XII, 502.

Cobb, B. 1952. "A Socio-Psychological Study of the Cancer Patient," Unpublished Doctoral Dissertation. University of Texas, Austin, Texas.

Coddington, R. D. 1972. "The Significance of Life Events as Etiologic Factors in the Diseases of Children. I: A Survey of Professional Workers, "Journal of Psychosomatic Research. $\therefore$ XVI, 1, 7-18.

Corson, Samuel A. 1966. "Neuroendocrine and Behavioral Response Patterns to Psychologic Stress and the Problems of the Target Tissue in Cerebrovisceral Pathology, "Annals of the New York Academy of Sciences, CXXV, Art. 3, 890-919.

Dixon, W. J., ed. 1968. Biomedical Computer Programs, Berkeley: University of $\mathrm{Cal}$ ifornia Press.

Drake, I. E. and E. R. Oetting. 1959. An MMPI Codebook for Counselors. Minneapolis: University of Minnesota Press.

Feder, Samuel L. 1966. "Psychological Considerations in the Care of Patients with Cancer," Annals of the New York Academy of Sciences, CXXV, Art. 3, 1020-1028. 
Gallagher, J. J. 1956. "MMPI Changes Concomitant with ClientCentered Therapy, "Basic Readings on the MMPI in Psychology and Medicine. Edited by George Welsh and W. Grant Dahlstrom. Minneapolis: University of Minnesota Press.

Green, W. A., Jr., I. E. Young, and S. N. Swisher. 1956. "Psychological Factors and Reticuloendothelial Disease: II. Observations on a Group of Women with Lymphomas and

- Leukemias," Psychosomatic Medicine, XVIII, 284.

Green, William A. and Gerald Miller. 1958. "Psychological Factors and Reticuloendothelial Disease: IV. Observations on a Group of Children and Adolescents with Leukemia: An Interpretation of Disease Development in Terms of the Mother-Child Unit," Psychosomatic Medicine, XX, No. 2.

Green, William A. 1959. "Role of a Vicarious Object in the Adaptation of Object Loss: II. Vicissitudes in the Role of the Vicarious Object," Psychosomatic Medicine, XXI, 6.

Greene, William A. 1966. "The Psychosocial Setting of the Development of Leukemia and Lymphoma," Annals of the New York Academy of Sciences, CXXV, Art. 3, 794-802.

Greene, William A. and Scott N. Swisher. 1969. "Psychological and Somatic Variables Associated with the Development and Course of Monozygotic Twins Discordant for Leukemia, Annals of the

- New York Academy of Sciences, C LXIV, Art. 2, 394-409.

Grossman, Jan C. and Russell Eisenman, 1972. "Birth Order, Authoritarianism and the Projection of Sex and Aggression," The Journal of Psychology, LXXX, 3-8.

Grinker, Roy R. 1966a. "Discussion of the Papers," Annals of the New York Academy of Sciences, CXXV, Art. 3, 874-876.

Grinker, Roy R. 1966b. "Psychosomatic Aspects of the Cancer Problem, "Annals of the New York Academy of Sciences, CXXV, Art, 3, 876-883.

Harlow, H. F. and M. K. Harlow. 1962. "Social Deprivation in Monkeys," Scientific America, CVII, 136-146. 
Harlow, H. F, and M. K. Harlow. 1965. The Affectional Systems in Behavior of Nonhuman Primates, Academic Press. New York, New York.

Harris, I. D. and D. Howard. 1968. "Birth Order and Responsibility," Journal of Marriage and Family, XXX, 427-432.

Hawkins, N. G., R. Davies, and T. H. Holmes. 1957. "Evidence of Psychosocial Factors in the Development of Pulmonary Tuberculosis," American Review of Tuberculosis Disease, LXXV, 5.

Henderson, J. G. 1966. "Denial and Repression as Factors in the Delay of Patients with Cancer Presenting Themselves to the Physician," Annals of the New York Academy of Sciences, CXXV, Art. 3, 856-865.

Hobson, Caroline J. and Grayburn W. Davis. 1970. "Social Work in Group Medical Practice," Psychosomatics, XI.

Holmes, Thomas H. and R. H. Rahe. 1967. "The Social Readjustment Rating Scale, Journal of Psychosomatic Research, XI, 213-218.

Holmes, T. H. 1968. "Life Style, Life Events and Disease," In Highlights of the Thirteenth Annual Conference, Veterans Administration Cooperative Studies in Psychiatry. Denver,

- Veterans Administration, Washington, D. C.

Iker, Howard. 1966. "The Psychological Setting of Uterine Cervical Cancer," Annals of the New York Academy of Sciences, CXXV, Art. 3, 807-814.

Katz, Jack, Thomas Gallagher, Leon Hellman, Edward Sachar, and Herbert Weiner. 1969. "Psychoendocrine Considerations in Cancer of the Breast," Annals of the New York Academy of Sciences, CIXIV, Art. 2,509-517.

Kissen, David M. 1960. "A Scientific Approach to Clinical Research in Psychosomatic'Medicine, "Psychosomatic Medicine, XX, $118-126$.

Kissen, David M., and H. J. Eysenck. 1962. "Personality in Male Lung Cancer Patients, " Journal of Psychosomatic Research, VI, 123. 
Kissen, David M. 1964a. "The Influence of Some Environmental Factors on Personality Inventory Scores in Psychosomatic Research, "Journal of Psychosomatic Research, VIII, 145.

Kissen, David M. 1964b. "Lung Cancer, Inhalation, and Personality," Psychosomatic Aspects of Neoplastic Disease, D. M. Kissen and L. L. LeShan, Eds. 3-11. Pitman, London, England.

Kisken, David M. 1965. "Possible Contribution of the Psychosomatic Approach to Prevention of Lung Cancer," Medical Officer, CXIV, 343-345.

Kissen, David M. 1966a. "The Value of a Psychosomatic Approach to Cancer," Annals of the New York Academy of Sciences, CXXV, Art. 3,777-780.

Kissen, David M. 1966b. "The Significance of Personality in Lung Cancer in Men," Annals of the New York Academy of Sciences, CXXV, Art. 3, 820-827.

Kissen, David M. 1966c. "Psychosocial Factors, Personality and Prevention in Lung Cancer," Medical Officer, CXVI, 135-138.

Kissen, David M. 1968. "Some Methodological Problems in Clinical Psychosomatic Research with Special Reference to Chest Disease," Psychosomatic Medicine, XXX, 324-335.

Kissen, David M. 1969. "A Scientific Approach to Clinical Research in Psychosomatic Medicine," Psychosomatic Medicine, $\mathrm{XXII}, 118-126$.

Kissen, David M. and L. G. S. Rao. 1969.. "Steroid Excretion Patterns and Personality in Lung Cancer," Annals of the New York Academy of Sciences, CIXIV, Art. 2, 476-483.

Kissen, David M., R. I. F. Brown, and Margaret Kissen. 1969. "A Further Report on Personality and Psychosocial Factors in Lung Cancer," Annals of the New York Academy of Sciences, CLXIV, Art. 2, 535-546.

LaBarba, Richard C. 1970. "Experimental and Environmental Factors in Cancer: A Review of Research with Animals," Psychosomatic Medicine, XXXII, 259-276. 
LeShan, I. I. and R. E. Worthington. 1955. "Some Psychologic Correlates of Neoplastic Disease: A Preliminary Report," Journal of Clinical Experimental Psychopathology, XVI, 281.

LeShan, L. L. and R. E. Worthington. 1956. "Personality as a Factor in the Pathogenesis of Cancer, "British Journal of Medical Psychology, XXIX, 49-56.

LaShan, L. I. 1959. "Psychological States as Factors in the Development of Malignant Disease: A Critical Review," Journal of the National Cancer Institute, XX, 1.

LeShan, Lawrence and M. Reznikoff. 1960. "A Psychological Factor Apparently Associated with Neoplastic Disease," Journal of Abnormal Social Psychology, IX, 439-440.

LeShan, Lawrence. 1966. "An Emotional Life-History Pattern Associated with Neoplastic Disease," Annals of the New York Academy of Sciences, CXXV, Art. 3, 780-794.

LeShan, Lawrence. 1969. "Early Experiences, Psychopathology, and Cancer: Discussion," Annals of the New York Academy of Sciences, CIXIV, Art. 2, 425-427.

Masuda, M. and T. H. Holmes. 1967. "Magnitude. Estimations of Social Readjustments, " Journal of Psychosomatic Research, XI, 219-225.

Masuda, Minorv., Kenneth P. Perko, and Robert G. Johnson. 1972. "Psysiological Activity and Illness History," Journal of Psychosomatic Research, XVI, 129-136.

Moos, R. H. and Solomon, G. F. 1965. "Psychologic Comparisons Between Woman with Rheumatoid Arthritis and Their NonArthritic Sisters. I. Personality Test and Interview Rating Data," Psychosomatic Medicine, XXVII, 135.

Moraczewski, Albert. 1970. "The Divorce of Psyche and Soma," Psychosomatics, XI.

Muslin, Hyman I., Kalman Gyarfas, and William J. Pieper. 1966. "Separation Experience and Cancer of the Breast," Annals of the New York Academy of Sciences, CXXV, Art. 2, $802-807$. 
Newton, G. 1964. "Early Experience and Resistence to Tumor Growth, "Psychosomatic Aspects of Neoplastic Disease. D. M. Kissen, ed. London: Pitman Medical Publishing Co. Ltd.

Obrach, C. E., A. M. Sutherland, and M. F. Bozeman. 1955. "Psychological Impact of Cancer and its Treatment: III. The Adaptation of Mothers to the Threatened Loss of Their Children Through Leukemia: Part II, " Cancer VIII, 20.

Palmer, R. 1966. "Birth Order and Identification," Journal of Consulting Psychologists. III, 129-135.

Perrin, G. M. and L. R. Pierce. 1959. "Psychosomatic Aspects of Cancer: A Review," Psychosomatic Medicine, V, 397.

Rahe, R. H., M. Meyer, M. Smith, G. Rajaer, and T. H. Holmes. 1964. "Social Stress and Illness Onset," Journal of Psychosomatic Research, XIII.

Rahe, R. H. and R. J. Arthur. 1968. "Life Change Patterns Surround ing Illness Experience," Journal of Psychosomatic Research, XI, 341 .

Renneker, R. and M. Cutler. 1952. "Psychologic Problems of Adjustment to Cancer of the Breast, " Journal of the American Medical Association, CXIVIII, 833-838.

Schmale, A. H., Jr. 1958. "Relation of Separation and Depression to Disease. I. A Report on a Hospitalized Medical Population," Psychosomatic Medicine, XX, 259-277.

Schmale, A. H. , Jr. and H. P. Iker. 1964. "The Affect of Hopelessness in the Development of Cancer. I. The Prediction of Uterine Cancer in Women with a Typical Cytology," Psychosomatic Medicine, XXVI, 634-635.

Schofield, W. 1956. "Changes Following Certain Therapies as Reflected in the MMPI, "Basic Readings on the MMPI in Psychology and Medicine. Edited by George Welsh and W. Grant Dahlstrom. Minneapolis: University of Minnesota Press.

Schwab, John J. 1970. "Comprehensive Medicine and the Concurrence of Psysical and Mental Illness, "Psychosomatics, XI. 
Shands, Harley C. 1966. "The Informational Impact of Cancer on the Structure of the Human Personality, "Annals of the New York Academy of Sciences, CXXV, Art. 3, 883-890.

Shands, Harley C. 1969. "Integration, Discipline and the Concept of Shape," Annals of the New York Academy of Sciences, CLXIV, Art. 2, 578-590.

$\checkmark$

Solomon, George F. 1969. "Emotion, Stress, the Central Nervous System, and Immunity," Annals of the New York Academy of Sciences, CIXIV, Art. 2, 335-344.

Southam, Chester M. 1969. "Discussion, Emotions, Immunology, and Cancer: How Might the Psyche Influence Neoplasia?" Annals of the New York Academy of Sciences, CIXIV, Art. 2, 473-476.

Spitz, R. A. 1945. "Hospitalism: An Inquiry into the Genesis of Psychiatric Conditions in Early Childhood," The Psychoanalytic Study of the Child. I. International Universities Press, New York, New York.

Spitz, Rene A. with W. G. Cobliner. 1965. The First Year of Life: A Psychoanalytic Study of Normal and Deviant Development of Object Relations. New York: International Universities Press, Inc.

Waxenberg, Sheldon E. 1966. "The Importance of the Communication of Feelings About Cancer," Annals of the New York Academy of Sciences, CXXV, Art. 3, 1000-1006.

Weis 8, Johnathan H. 1968. "Birth Order and Asthma in Children," Journal of Psychosomatic Research, XII, 137-140.

Weiss, Johnathan H. 1969. "Host-Parasite Relationship," Annals of the New York Academy of Sciences, C IXIV, Art. 2, 445.

Weiss, Johnathan H. 1970. "Birth Order and Physiological Stress Response," Child Development, XI, 461-470.

Wolff, H. G. (Ed.). 1950. "Life Stress and Bodily Disease," Professional Association for Research in Nervous and Mental Diseases, XXIX, 1059. 
APPENDIX A

CODE SHEET \#1

\begin{tabular}{|c|c|}
\hline Column & Code \\
\hline $1-3$ & Three Dig it Case Numier \\
\hline $4-5$ & Child's Age \\
\hline 6 & $\underline{\text { Sex }}$ \\
\hline 7 & Number of Siblings \\
\hline 8 & $\begin{array}{l}\text { Sibling Rank } \\
\text { 1. Oldest } \\
\text { 2. Middle } \\
\text { 3. Young est }\end{array}$ \\
\hline $9-10$ & Month of Diagnosis \\
\hline 11 & $\begin{array}{cc}\text { Year of Diagnosis } \\
0 . & 1965 \\
\text { 1. } & 1966 \\
\text { 2. } & 1967 \\
\text { 3. } & 1968 \\
\text { 4. } & 1969 \\
\text { 5. } & 1970 \\
\text { 6. } & 1971 \\
\text { 7. } & 1972\end{array}$ \\
\hline $12-21$ & $\begin{array}{l}\text { Child's Questionnaire } \\
\text { 1. True } \\
\text { 2. False }\end{array}$ \\
\hline $22-31$ & $\frac{\text { Child's Questionnaire }}{\text { 1. Agree }}$ \\
\hline
\end{tabular}


Column

Code

$32-34$

$35-37$

$38-40$

$41-43$

$44-46$

$47-48$

$49-50$

$51-52$

$53-54$

$55-56$

$5 z-58$

$59-60$

$61-62$

$63-64$

$65-66$

$67-68$

$69-70$

80
Social Adjustment Rating Scale - Total

Social Adjustment Rating Scale - Preschool Years

Social Adjustment Rating Scale -

Elementary Years

Social Adjustment Rating Scale -

Junior High Years

Social Adjustment Rating Scale - Senior High Years

Preschool Ranks - Number 1

Preschool Ranks - Number 2

Preschool Ranks Number 3

Elementary School Ranks - Number 1

Elementary School Ranks - Number 2

Elementary School Ranks - Number 3

Junior High School Ranks - Number 1

Junior High School Ranks - Number 2

Junior High School Ranks - Number 3

Senior High School Ranks - Number 1

Senior High School Ranks - Number 2

Senior High School Ranks - Number 3

Code

A. Experimental Subjects

B. Control Subjects 


\section{APPENDIX B}

CODE SHEET \#2

\begin{tabular}{|c|c|}
\hline Column & Code \\
\hline $1-3$ & Three Digit Case Number \\
\hline $4-5$ & Mother's Age \\
\hline $6-7$ & Father's Age \\
\hline 8 & $\begin{array}{l}\text { Mother's Employment Status } \\
\text { 1. Working } \\
\text { 2. Non-working } \\
\text { 3. Student }\end{array}$ \\
\hline 9 & $\begin{array}{l}\text { Father's Employment Status } \\
\text { 1. Working } \\
\text { 2. Non-working } \\
\text { 3. Student }\end{array}$ \\
\hline 10 & \begin{tabular}{ll}
\multicolumn{2}{l}{ Income } \\
1. & Under $\$ 3,999$ \\
2. $\$ 4,000-\$ 5,999$ \\
3. $\$ 6,000-\$ 7,999$ \\
4. $\$ 8,000-\$ 9,999$ \\
5. $\$ 10,000$ and above
\end{tabular} \\
\hline 11 & $\begin{array}{l}\text { Child's Birthright } \\
\text { 1. Natural child } \\
\text { 2. Adopted child }\end{array}$ \\
\hline 12 & $\begin{array}{l}\text { Child's Living Arrangement } \\
\text { 1. Both natural parents } \\
\text { 2. Natural mother } \\
\text { 3. Natural father }\end{array}$ \\
\hline
\end{tabular}




\begin{tabular}{|c|c|}
\hline Column & Code \\
\hline 13 & $\begin{array}{ll}\text { Mother's Marital Status } \\
\text { 1. Married } \\
\text { 2. Divorced } \\
\text { 3. Remarried } \\
\text { 4. Deceased }\end{array}$ \\
\hline 14 & $\begin{array}{cl}\frac{\text { Father's Marital Status }}{} \\
\text { 1. Married } \\
\text { 2. Divorced } \\
\text { 3. Remarried } \\
\text { 4. Deceased }\end{array}$ \\
\hline 15 & $\begin{array}{l}\frac{\text { Mother's MMPI }}{\text { 1. Question - OK }} \\
\text { 2. Question } 30+\end{array}$ \\
\hline 16 & MMPI - I Score (Validity Scale) \\
\hline $17-18$ & F Score (Validity Scale) \\
\hline $19-20$ & MMPI - K Score (Validity Scale) \\
\hline $21-22$ & MMPI - Scale 1 (Hypochondriasis) \\
\hline $23-24$ & MMPI - Scale 2 (Depression) \\
\hline $25-26$ & MMPI - Scale 3 (Hysteria) \\
\hline $27-28$ & MMPI Scale 4 (Psychopathic Deviate) \\
\hline $29-30$ & $\begin{array}{l}\text { MMPI Scale } 5 \text { (Masculinity - } \\
\text { Femininity) }\end{array}$ \\
\hline $31-32$ & MMPI - Scale 6 (Paranoid) \\
\hline $33-34$ & MMPI - Scale 7 (Psychasthenia) \\
\hline $35-36$ & MMPI - Scale 8 (Schizophrenia) \\
\hline $37-38$ & MMPI - Scale 9 (Hypomania) \\
\hline $39-40$ & MMPI - Scale 0 (Socialibility) \\
\hline
\end{tabular}




\begin{tabular}{|c|c|}
\hline Column & Code \\
\hline 41 & $\begin{array}{l}\text { Father's MMPI } \\
\text { 1. Question - OK } \\
\text { 2. Question - 30t }\end{array}$ \\
\hline 42 & MMPI - I Score (Validity Scale) \\
\hline $43-44$ & MMPI - F Score (Validity Scale) \\
\hline $45-46$ & MMPI - K Score (Validity Scale) \\
\hline $47-48$ & MMPI - Scale 1 (Hypochondriasis) \\
\hline $49-50$ & MMPI - Scale 2 (Depression) \\
\hline $51-52$ & Scale 3 (Hysteria) \\
\hline $53-54$ & MMPI - Scale 4 (Psychopathic Deviate) \\
\hline $55-56$ & $\begin{array}{r}\text { MMPI - Scale } 5 \text { (Masculinity - } \\
\text { Femininity) }\end{array}$ \\
\hline $57-58$ & MMPI - Scale 6 (Paranoid) \\
\hline $59-60$ & MMPI - Scale 7 (Psychasthenia) \\
\hline $61-62$ & MMPI - Scale 8 (Schizophrenia) \\
\hline $63-64$ & MMPI - Scale 9 (Hypomania) \\
\hline $65-66$ & MMPI - Scale 0 (Socialibility) \\
\hline 80 & $\begin{array}{l}\text { Code } \\
\text { C. Experimental Group } \\
\text { D. Control Group }\end{array}$ \\
\hline
\end{tabular}




\section{APPENDIX C}

\section{DATA COVER LETTER}

\section{RESEARCH STUDY ON LEUKEMIA}

The University of Oregon Medical School is a teaching and research hospital. We are seeking your help in under standing the question "Why Leukemia?"

Recent research on the causes and treatment of this disease may give new hope to the thousands of people who are either directly, or indirectly, affected each year. Our study seeks to understand some of the psychological and social aspects of the disease.

We sincerely hope for your cooperation in this project, as your help is vital for the scientific understanding of this disease. It is through the help of people like yourself that medical progress is made.

We are asking you to fill out the following information:

1. Social Readjustment Rating Questionnaire

a) check each item that applies to the identified child.

b) number those items according to their importance to your child. For example, if the "Loss of a job by a parent" is the most important event that happened to your child in his preschool years, you would put the number one (1) beside it. A number two (2) for the second most important, and so on.

c) Give the approximate date, month and year, for each event. 
2. Minnesota Multiphasic Personality Inventory (MMPI)

a) fill out your answer sheet according to the directions on the test booklet.

b) both you and your husband (or wife) must each fill out a separate test.

If you have any questions, please ask the person who gave you the questionnaire, and thank you for your help. 


\section{APPENDIX D}

\section{SOCIAL READJUSTMENT RATING QUESTIONNAIRE (AS PRESENTED TO SUBJECTS)}

\section{PRESCHOOL AGE GROUP}

1. Birth of a brother or sister

2. Decrease in number of arguments between parents

3. Beginning nursery school

4. Serious illness requiring hospitalization of parent

5. Increase in number of arguments between parents

6. Less of job by a parent

7. Having a visible congenital deformity

8. Change in child's acceptance by peers

9. Decrease in number of arguments with parents

10. Change to a new nursery school

11. Increase in number of arguments with parents

12. Change in father's occupation requiring increased absence from home

13. Outstanding personal achievement

14. Serious illness requiring hospitalization of child

15. Divorce of parents

16. Marital separation of parents

17. Jall sentence of parent for 1 year or more

18. Marriage of parent to stepparent

19. Addition of third adult to family (i. e. grandparent, etc.)

20. Death of a brother or sister

21. Change in parents' financial status

22. Discovery of being an adopted child

23. Death of a grandparent

24. Mother beginning to work

25. Death of a close friend

26. Serious illness requiring hospitalization of brother or sister

27. Death of a parent

28. Brother or sister leaving home

29. Acquiring a visible deformity

30. Jail sentence of parent for 30 days or less 


\section{ELEMENTARY SCHOOL AGE GROUP}

$\checkmark$

EVENTS

YALUES

DATE

1. Birth of a brother or sister

2. Death of a parent

3. Mother beginning to work

4. Change in child's acceptance by peers

5. Serious illness requiring hospitalization of brother or sister

6. Jail sentence of parent for 1 year or more

7. Marriage of parent to stepparent

8. Addition of third adult to family (i.e. grandparent, etc.)

9. Divorce of parents

10. Serious illness requiring hospitalization of child

11. Marital separation of parents

12. Increase in number of arguments between parents

13. Change in father's occupation requiring increased absence from home

14. Suspension from school

15. Increase in number of arguments with parents

16. Serious illness requiring hospitalization of parent

17. Beginning another school year (second grade, third grade, etc.)

18. Discovery of being an adopted child

19. Decrease in number of arguments between parents

20. Pregnancy in unwed teenage sister

21. Move to a new school district

22. Death of a close friend

23. Decrease in number of arguments with parents

24. Becoming involved with drugs or alcohol

25. Beginning school

26. Becoming a full fledged member of a church

27. Death of a brother or sister

28. Change in parental financial status

29. Death of a grandparent

30. Brother or sister leaving home

31. Acquiring a visible deformity

32. Outstanding personal achievement

33. Jall sentence of parent for $\mathbf{3 0}$ days or less

34. Loss of job by a parent

35. Having a visible congenital deformity

36. Failure of a grade in school 


\section{SOCIAL READJUSTMENT RATING QUESTIONNAIRE}

\section{、 JUNIOR HIGH SCHOOL AGE GROUP}

1. Birth of a brother or sister

2. Pregnancy in unwed teenage sister

3. Marital separation of parents

4. Suspension from school

5. Beginning to date

6. Serious illness requiring hospitalization of brother or sister

7. Not making an extracurricular activity he/she wanted to be involved in (i.e. athletic team, band, etc.)

8. Divorce of parents

9. Death of a close friend

10. Beginning junior high school

11. Increase in number of arguments between parents

12. Serious illness requiring hospitalization of parent

13. Becoming involved with drugs or alcohol

14. Change in child's acceptance by peers

15. Fallure of a grade in school

16. Unwed pregnancy of child

17. Discovery of being an adopted child

18. Jail sentence of a parent for 1 year or more

19. Death of a parent

20. Move to a new school district

21. Decrease in number of arguments between parents

22. Fathering an unwed pregnancy

23. Having a visible congenital deformity

24. Death of a brother or sister

25. Acquiring a visible deformity

26. Breaking up with a boyfriend

27. Decrease in num ber of arguments with parents

28. Increase in number of arguments with perents

29. Death of a grandparent

30. Becoming a full fledged member of a church

31. Addition of third adult to family (i. e. grandparent, etc.)

32. Change in parents' financial status

33. Jail sentence of a parent for $\mathbf{3 0}$ days or less

34. Outstanding personal achievement

35. Change in father's occupation requiring increased absence from home

36. Mother beginning to work

37. Brother or sister leaving home

38. Marriage of parent to stepparent

39. Serious illness requiring hospitalization of child

40. Loss of job by a parent 
SOCLAL READJUSTMENT RATING QUESTIONNAIRE

SENIOR HIGH SCHOOL AGE GROUP

EVENTS

VALUES

DATE

1. Birth of a brother or sister

2. Increase in number of arguments with parents

3. Fathering an unwed pregnancy

4. Death of a parent

5. Not making an extracurricular activity he/she wanted to be involved in (i.e. athletic team, band, etc.)

6. Mother beginning to work

7. Death of a close friend

8. Suspension from school

9. Being accepted at a college of his/her choice

10. Unwed pregnancy of child

11. Pregnancy in unwed teenage sister

12. Death of a grandparent

13. Addition of third adult to family (i. e. grandparent, etc.)

14. Decrease in number of arguments with parents

15. Beginning to date

16. Serious illness requiring hospitalization of brother or sister

17. Serious illness requiring hospitalization of child

18. Change in parents' financial status

19. Jail sentence of a parent for $\mathbf{3 0}$ days or less

20. Decrease in number of arguments between parents

21. Increase in number of arguments between parents

22. Discovery of being an adopted child

23. Marriage of parent to stepparent

24. Breaking up with a boyfriend or girlfriend

25. Having a visible congenital deformity

26. Change in father's occupation requiring increased absence from home

27. Becoming a full fledged member of a church

28. Failure of a grade in school

29. Acquiring a visible deformity

30. Getting married

31. Change in child's acceptance by peers

32. Death of a brother or sister

33. Brother or sister leaving home

34. Serious illness requiring hospitalization of parent

35. Becoming involved with drugs or alcohol

36. Divorce of parents

37. Move to a new school district

38. Outstanding personal achievement

39. Loss of job by a parent

40. Marital separation of parents

41. Beginning senior high school

42. Jail sentence of a parent for 1 year or more 


\section{APPENDIX E \\ CHILD'S QUESTIONNAIRE, TRUE-FALSE CODED \\ FOR ACTIVE-PASSIVE RESPONSE}

Put a check (X) by those that are true.

1. I rarely argue with my parents.

2. I have lots of fights with my friends.

3. I don't mind people bossing me around.

4. I get mad when people tell me to hurry, and shout at them.

5. When someone takes something from me I tell my mother or teacher.

6. I try not to let people know I am mad. .

7. "Horsing around" gets me in trouble at school.

8. I do not mind kids making fun of me.

9. When I am mad I sometimes break things.

10. I like to get back at my teacher when she picks on me.
Aggression Code Active Passive

$\mathbf{F}$

$\mathbf{T}$

$\mathbf{T}$

F

F

$\mathrm{T}$

$\mathbf{T}$

F

F $\quad$ T

F $\quad$ T

T $\quad \mathbf{F}$

$\mathbf{F} . \quad \mathbf{T}$

$\mathbf{T} \quad \mathbf{F}$

$\mathbf{T}$

$\mathbf{F}$ 


\section{CHILD'S QUESTIONNAIRE, AGREE-DISAGREE CODED FOR ACTIVE-PASSIVE RESPONSE}

Put a circle around the word "agree" if you agree with the sentence, or put a circle around the word "disagree" if you don't agree with it.

Argressive Code

Active Passive

agree disagree 1. It's Ok to argue with your parents when you think they are wrong.

$\mathbf{F}$ $\mathbf{T}$

agree disagree 2. If someone you know steals your bell you should ask your parents to buy you another one.

agree disagree 3. A dog should never be hit or kicked even when it is bad.

agree disagree 4. Cutting up in class is a good way to get even with your teacher.

$T$

F

$\mathbf{T}$

agree disagree 5. You ahould ignore someone who is being mean to you.

agree disagree 6. When you are mad it feels good to ldick a wall or break something.

F

$\mathbf{T}$

agree disagree 7. You should always go to bed when you're suppose to, even If you don't want to.

$\mathbf{T}$

$\mathbf{F}$

agree disagree 8. If a kid trys to get you in trouble, you should still be nice to him.

F

$\mathbf{T}$

-agree disagree 9. When another kid is playing with a toy you want, it is Ok to take it away.

$\mathbf{T}$

$\mathbf{F}$

agree disagree 10. The best thing to do if someone hits you is to hit them back. 


\title{
APPENDIX F
}

\author{
TABLE XII
}

SOCIAL READJUSTMENT RATING SCALE: RANKS, LIFE EVENTS, LIF E CHANGE UNITS AND ITEM FREQUENCIES BY GROUP

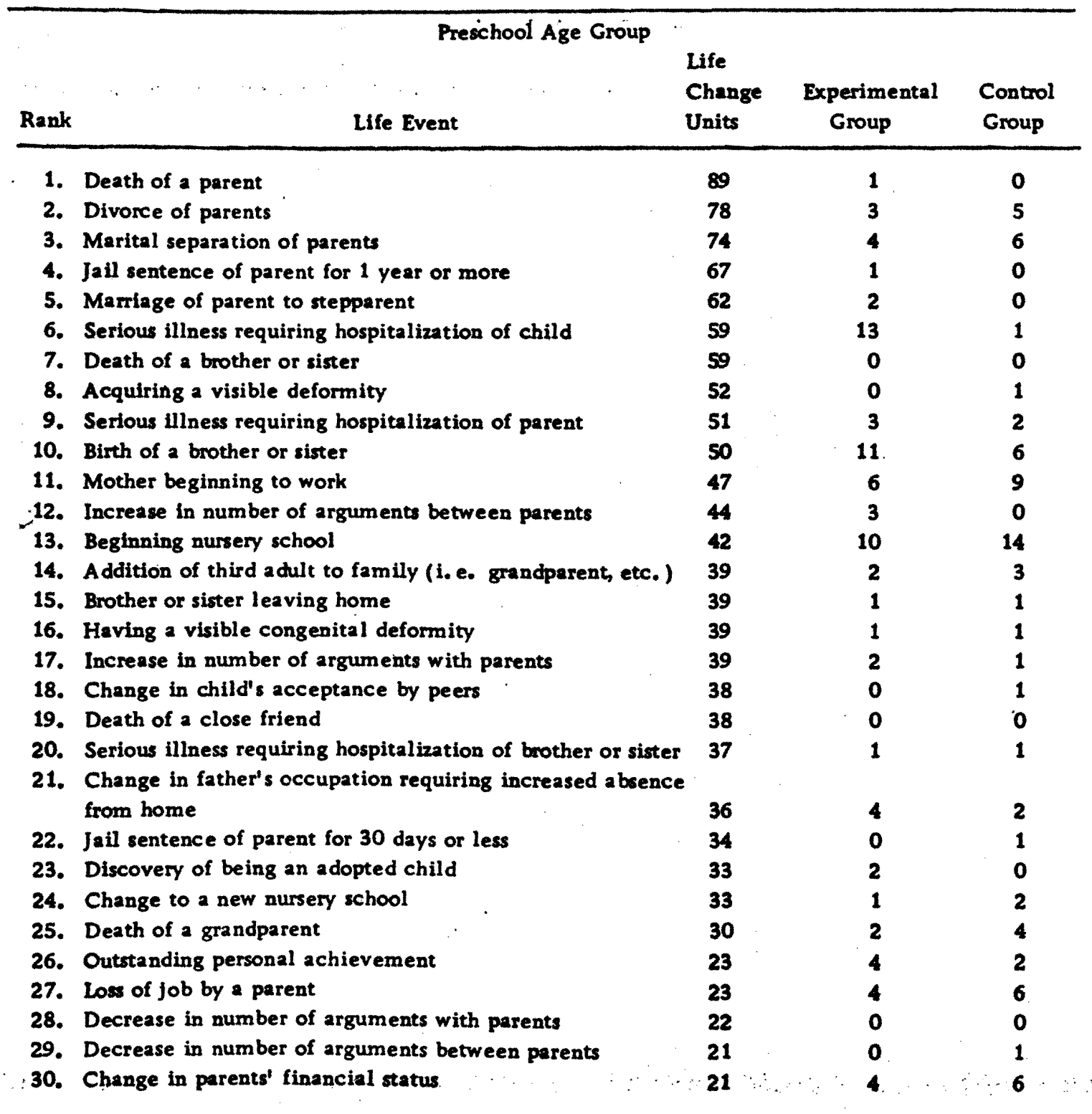


TABLE XII CONTINUED

\begin{tabular}{|c|c|c|c|c|}
\hline \multicolumn{5}{|c|}{ Elementary School Age Group } \\
\hline Rank & Life Event & $\begin{array}{l}\text { Life } \\
\text { Change } \\
\text { Units }\end{array}$ & $\begin{array}{l}\text { Experimental } \\
\text { Group }\end{array}$ & $\begin{array}{l}\text { Control } \\
\text { Group }\end{array}$ \\
\hline 1. & Death of a parent & 91 & 0 & 0 \\
\hline 2. & Divorce of parents & 84 & 2 & 0 \\
\hline 3. & Marital separation of parents & 78 & 2 & 0 \\
\hline 4. & Acquiring 2 visible deformity & 69 & $\mathbf{0}$ & 0 \\
\hline 5. & Death of a brother or sister & 68 & $\mathbf{0}$ & 0 \\
\hline 6. & Jail sentence of parent for 1 year or more & 67 & 0 & 0 \\
\hline 7. & Marriage of parent to stepparent & 65 & 1 & 0 \\
\hline 8. & Serious illness requiring hospitalization of child & 62 & 7 & 4 \\
\hline 9. & Becoming involved with drugs or alcohol & 61 . & 1 & 1 \\
\hline 10. & Having a visible congenital deformity & 60 & $\mathbf{0}$ & 0 \\
\hline 11. & Failure of a grade in school & 57 & 0 & 1 \\
\hline 12. & Serious illness requiring hospitalization of parent & 55 & 2 & 3 \\
\hline 13. & Death of a close friend & 53 & 1 & 1 \\
\hline 14. & Discovery of being an adopted child & 52 & 1 & 0 \\
\hline 15. & Increase in number of arguments between parents & 51 & 1 & 0 \\
\hline 16. & Change in child's acceptance by peers & 51 & 0 & 2 \\
\hline 17. & Birth of a brother or sister & 50 & 3 & 0 \\
\hline 18. & Increase in number of arguments with parents & 47 & 1 & 6 \\
\hline 19. & Move to 2 new school district & 46 & 6 & 5 \\
\hline 20. & Beginning school & 46 & 6 & 13 \\
\hline 21. & Suspension from school & 46 & 0 & 0 \\
\hline \multirow[t]{2}{*}{22.} & Change in father's occupation requiring increased absence & & & \\
\hline & from home & 45 & 3 & 2 \\
\hline 23. & Mother beginning to work & 44 & $\mathbf{5}$ & 6 \\
\hline 24. & Jail sentence of parent for 30 days or less & 44 & 0 & 0 \\
\hline 25. & Serious illness requiring hospitalization of brother or sister & 41 & 1 & 0 \\
\hline 26. & Addition of third adult to family (i.e. grandmother, etc.) & 41 & 2 & 0 \\
\hline 27. & Outstanding personal achievement & 39 & 4 & 6 \\
\hline 28. & Loss of job by a parent & 38 & 3 & 1 \\
\hline 29. & Death of a grandparent & 38 & 3 & 6 \\
\hline 30. & Brother or sister leaving home & 36 & 2 & 2 \\
\hline 31. & Pregnancy in unwed teenage sister & 36 & 0 & 0. \\
\hline 32. & Change in parents' financial status & 29 & 4 & 3 \\
\hline 33. & Beginning another school year & 27 & 8 & 11 \\
\hline 34. & Decrease in number of arguments with parents & 27 & 0 & 0 \\
\hline 35. & Decrease in number of arguments between parents & 25 & 1 & 1 \\
\hline 36. & Becoming a full fledged member of a church & 25 & 1 & 2 \\
\hline
\end{tabular}


TABLE XII CONTINUED

\begin{tabular}{|c|c|c|c|c|}
\hline \multicolumn{5}{|c|}{ Junior High School Age Group } \\
\hline Rank & Life Event & $\begin{array}{l}\text { Life } \\
\text { Change } \\
\text { Units }\end{array}$ & $\begin{array}{l}\text { Experimental } \\
\text { Group }\end{array}$ & $\begin{array}{l}\text { Control } \\
\text { Group }\end{array}$ \\
\hline 1. & Umwed pregnancy of child & 95 & 0 & $\mathbf{0}$ \\
\hline 2. & Death of a parent & 94 & 0 & $\mathbf{0}$ \\
\hline 3. & Divorce of parents & 84 & $\mathbf{0}$ & $\mathbf{0}$ \\
\hline 4. & Acquiring a visible deformity & 83 & $\mathbf{0}$ & $\mathbf{0}$ \\
\hline 5. & Marital separation of parents & 77 & $\mathbf{0}$ & $\mathbf{0}$ \\
\hline 6. & Jall sentence of parent for 1 year or more & 76 & 0 & $\mathbf{0}$ \\
\hline 7. & Fathering an unwed pregnancy & 76 & $\mathbf{0}$ & 0 \\
\hline 8. & Death of a brother or sister & 71 & 0 & $\mathbf{0}$ \\
\hline 9. & Having a visible congenital deformity & 70 & 0 & $\mathbf{0}$ \\
\hline 10. & Discovery of being an adopted child & 70 & 0 & $\mathbf{0}$ \\
\hline 11. & Becoming involved with drugs or alcohol & 70 & $\mathbf{0}$ & $\mathbf{0}$ \\
\hline 12. & Change in child's acceptance by peers & 68 & $\mathbf{0}$ & 1 \\
\hline 13. & Death of a close friend & 65 & 0 & 0 \\
\hline 14. & Marriage of parent to stepparent & 63 & $\mathbf{0}$ & $\mathbf{0}$ \\
\hline 15. & Fallure of a grade in school & 62 & $\mathbf{0}$ & $\mathbf{0}$ \\
\hline 16. & Pregnancy in unwed teenage sister & 60 & $\mathbf{0}$ & $\mathbf{0}$ \\
\hline 17. & Sertous illness requiring hospitalization of child & 59 & 1 & 0 \\
\hline 18. & Beginning to date & $\mathbf{5 5}$ & 1 & 1 \\
\hline 19. & Suspension from school & 54 & $\mathbf{0}$ & 0 \\
\hline 20. & Serious illness requiring hospitalization of parent & 54 & 1 & 1 \\
\hline 21. & Move to a new school district & $\mathbf{5 2}$ & 1 & $\mathbf{0}$ \\
\hline 22. & Jail sentence of parent for 30 days or less & so & $\mathbf{0}$ & 0 \\
\hline 23. & Birth of a brother or sister & so & $\mathbf{0}$ & 1 \\
\hline 24. & Not making an extracurricular activity he/she wanted & 49 & 0 & 1 \\
\hline 25. & Loss of job by a parent & 48 & $\mathbf{0}$ & 0 \\
\hline 26. & Increase in number of arguments between parents & 48 & $\mathbf{0}$ & 0 \\
\hline 27. & Breaking up with a boyfriend or girlfriend & 47 & $\mathbf{0}$ & 1 \\
\hline 28. & Increase in number of arguments with parents & 46 & 0 & 1 \\
\hline 29. & Beginning Junior High School & 45 & 10 & 3 \\
\hline 30. & Outstanding personal achievement & 45 & $\mathbf{0}$ & 1 \\
\hline 31. & $\begin{array}{l}\text { Serious illness requiring hospitalization of brother or sister } \\
\text { Change in father's occupation requiring increased absence }\end{array}$ & 44 & 2 & $\mathbf{0}$ \\
\hline & from home & 42 & 0 & 0 \\
\hline 33. & Change in parents' financial status & 40 & $\mathbf{0}$ & 1 \\
\hline 34. & Mother beginning to work & 36 & 0 & 0 \\
\hline 35. & Death of a grandparent & 35 & $\mathbf{0}$ & $\mathbf{0}$ \\
\hline 36. & Addition of third adult to family (1. e. grandparent, etc.) & 34 & 0 & 0 \\
\hline 37. & Brother or sister leaving home & 33 & 1 & 1 \\
\hline 38. & Decrease in number of arguments between parents & 29 & 0 & 0 \\
\hline 39: & Decrease in number of arguments with parents & 29 & $\mathbf{0}$ & 0 \\
\hline 40. & Becoming a full fledged member of a church & 28 & 0 & 0 \\
\hline
\end{tabular}


TABLE XII CONTINUED

\begin{tabular}{|c|c|c|c|c|}
\hline Rank & Senior High School Age Grou & $\begin{array}{l}\text { up } \\
\text { Life } \\
\text { Change } \\
\text { Units }\end{array}$ & $\begin{array}{l}\text { Experimental } \\
\text { Group }\end{array}$ & $\begin{array}{l}\text { Control } \\
\text { Group }\end{array}$ \\
\hline 1. & Getting married & 101 & 0 & 0 \\
\hline 2. & Unwed pregnancy of child & 92 & 0 & 0 \\
\hline 3. & Death of a parent & 87 & 1 & 0 \\
\hline 4. & Acquiring a visible deformity & 81 & 0 & $\mathbf{0}$ \\
\hline 5. & Divorce of parents & 77 & 0 & 0 \\
\hline 6. & Fathering an unwed pregnancy & 77 & 0 & 0 \\
\hline 7. & Becoming involved with drugs or alcohol & 76 & 0 & 0 \\
\hline 8. & Jail sentence of parent for 1 year or more & 75 & 0 & $\mathbf{0}$ \\
\hline 9. & Marital separation of parents & 69 & 0 & $\mathbf{0}$ \\
\hline 10. & Death of a brother or sister & 68 & 0 & 0 \\
\hline 11. & Change in child's acceptance by peers & 67 & $\mathbf{0}$ & 0 \\
\hline 12. & Pregnancy in unwed teenage sister & 64 & $\mathbf{0}$ & 0 \\
\hline 13. & Discovery of being an adopted child & 64 & 0 & 0 \\
\hline 14. & Marriage of parent to stepparent & 63 & 0 & 0 \\
\hline 15. & Death of a close friend & 63 & $\mathbf{0}$ & 0 \\
\hline 16. & Having a visible congenital deformity & 62 & $\mathbf{0}$ & $\mathbf{0}$ \\
\hline 17. & Serious illness requiring hospitalization of child & 58 & 1 & 0 \\
\hline 18. & Fallure of a grade in school & 56 & 0 & 0 \\
\hline 19. & Move to a new school district & 56 & $\mathbf{0}$ & $\mathbf{0}$ \\
\hline 20. & Not making an extracurricular activity he/she wanted & 55 & 1 & 0 \\
\hline 21. & Serious illness requiring hospitalization of parent & $\mathbf{5 5}$ & 1 & $\mathbf{0}$ \\
\hline 22. & Jall sentence of parent for 30 days or less & 53 & $\mathbf{0}$ & $\mathbf{0}$ \\
\hline 23. & Breaking up with a boyfriend or girlfriend & 53 & $\mathbf{0}$ & 0 \\
\hline 24. & Beginning to date & 51 & 0 & 0 \\
\hline 25. & Suspension from school & 50 & $\mathbf{0}$ & 0 \\
\hline 26. & Birth of a brother or sister & 50 & 0 & 0 \\
\hline 27. & Increase in number of arguments with parents & 47 & 0 & 0 \\
\hline 28. & Increase in number of arguments between parents & 46 & 0 & 0 \\
\hline 29. & Loss of job by 2 parent & 46 & $\mathbf{0}$ & 0 \\
\hline 30. & Outstanding personal achievement & 46 & 1 & 1 \\
\hline 31. & Change in parents' financial status & 45 & $\mathbf{0}$ & 0 \\
\hline 32. & Being accepted at a college of his/her choice & 43 & $\mathbf{0}$ & $\mathbf{0}$ \\
\hline 33. & Beginning senior high school & 42 & 1 & 1 \\
\hline 34. & Serious illness requiring hospitalization of brother or sister & 41 & 0 & $\mathbf{0}$ \\
\hline \multirow[t]{2}{*}{35.} & Change in father's occupation requiring increased absence & & & \\
\hline & from home & 38 & $\mathbf{0}$ & 1 \\
\hline 36. & Brother or sister leaving home & 37 & 1 & $\mathbf{0}$ \\
\hline 37. & Death of a grandparent & 36 & 1 & 0 \\
\hline 38. & Addition of third adult to family (i. e. grandparent, etc.) & 34 & $\mathbf{0}$ & 0 \\
\hline 39. & Becoming a full fledged member of a church & 31 & 0 & 0 \\
\hline 40. & Decrease in number of arguments between parents & 27 & 0 & 0 \\
\hline 41. & Decrease in number of arguments with parents & 26 & 0 & 0 \\
\hline 42. & Mother beginning to work & 26 & 0 & 0 \\
\hline
\end{tabular}




\section{APPENDIX G}

TABLE XIII

SOCIAL ADJUSTMENT RATING QUESTIONNAIRE:

TOTAL SCORES BY CASE NUMBER AND GROUP

\begin{tabular}{lccc}
\hline $\begin{array}{c}\text { Case } \\
\text { Number }\end{array}$ & $\begin{array}{c}\text { Experimental } \\
\text { Group }\end{array}$ & $\begin{array}{c}\text { Case } \\
\text { Number }\end{array}$ & $\begin{array}{c}\text { Control } \\
\text { Group }\end{array}$ \\
\hline 101 & 790 & 201 & 275 \\
103 & 485 & 203 & 268 \\
104 & 340 & 204 & 551 \\
105 & 566 & 205 & 275 \\
106 & 101 & 206 & 292 \\
107 & 207 & 207 & 000 \\
108 & 589 & 208 & 388 \\
109 & 339 & 209 & 131 \\
110 & 325 & 210 & 568 \\
111 & 280 & 211 & 327 \\
112 & 322 & 212 & 596 \\
113 & 398 & 213 & 430 \\
114 & 161 & 214 & 306 \\
115 & 331 & 215 & 139 \\
116 & 258 & 216 & 139 \\
117 & 180 & 217 & 459 \\
118 & 1066 & 218 & 551 \\
119 & 369 & 219 & 156 \\
121 & 222 & 221 & 108 \\
122 & 059 & 222 & .44 \\
124 & 059 & 224 & 153 \\
125 & 249 & 225 & 555 \\
& & & \\
\hline
\end{tabular}




\section{APPENDIX H}

TABLE XIV

FREQUENCY DISTRIBUTION OF SOCLAL ADJUSTMENT RATINC QUESTIONNAIRE: FOURTEEN OBJECT LOSS EVENTS BY AGE AND GROUP

\begin{tabular}{|c|c|c|c|c|c|c|c|c|c|c|c|}
\hline \multirow{3}{*}{ 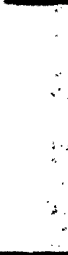 } & \multirow[b]{3}{*}{ Object Loss Events } & \multicolumn{5}{|c|}{ Experimental } & \multicolumn{5}{|c|}{ Control } \\
\hline & & $\begin{array}{l}\text { Preschool } \\
\text { Age }\end{array}$ & $\begin{array}{l}\text { Elementary } \\
\text { Age }\end{array}$ & $\begin{array}{r}\text { Junior } \\
\text { High } \\
\text { Age }\end{array}$ & $\begin{array}{c}\text { Senior } \\
\text { High } \\
\text { Age }\end{array}$ & Total & $\begin{array}{l}\text { Pre- } \\
\text { School }\end{array}$ & $\begin{array}{c}\text { Elementary } \\
\text { Age }\end{array}$ & $\begin{array}{l}\text { Junior } \\
\text { High } \\
\text { Age }\end{array}$ & $\begin{array}{l}\text { Senior } \\
\text { High } \\
\text { Age }\end{array}$ & Total \\
\hline & & No. & No. & No. & No. & No. & No. & No. & No. & No. & No. \\
\hline 1. & Birth of brother or sister & 11 & 3 & & & 14 & 6 & & 1 & & 7 \\
\hline 2. & Serious illness-hosp. of parent & 3 & 2 & 1 & 1 & 7 & 2 & 3 & 1 & & 6 \\
\hline 3. & Change of father's occupation & 3 & 3 & & & 6 & 3 & 2 & & 1 & 6 \\
\hline 4. & Divorce of parents & 3 & 2 & & & 5 & 5 & & & & 5 \\
\hline s. & Marital sep, of parents & 4 & 2 & & & 6 & 6 & & & & 6 \\
\hline 6. & Jail sentence of parent for 1 year & 1 & 0 & & & 1 & & & & . & \\
\hline 7. & Marriage of parent to step-parent & 2 & 1 & & & 3 & & & & & \\
\hline 8. & Death of brother or sister & 0 & 0 & & & & & & & & \\
\hline 9. & Discovery of being adopted & 2 & 1 & & & 3 & & & & & \\
\hline 10. & Death of Grandparent & 2 & 3 & & 1 & 6 & 4 & 6 & & & 10 \\
\hline 1. & Move to new school district & 0 & 6 & 1 & & 7 & & 5 & & & $\mathbf{s}$ \\
\hline 2. & Mother begins to work & 6 & $\mathbf{s}$ & & & 11 & 9 & 6 & & & 15 \\
\hline 3. & Death of close friend & 0 & 1 & & & 1 & & 1 & & & 1 \\
\hline 4. & Death of a parent & 1 & 0 & & 1 & 2 & & & & & \\
\hline & $\therefore$ & - & - & - & - & - & - & - & - & - & - \\
\hline & Totals & 38 & 29 & 2 & 3 & 72 & 35 & 23 & 2 & 1 & 61 \\
\hline
\end{tabular}




\section{APPENDIX I}

\section{TABLE XV}

RESULTS OF MMPI SCALE SCORES BY PARENT AND GROUP: MEANS AND STANDARD DEVIATIONS

\begin{tabular}{|c|c|c|c|c|c|c|c|c|}
\hline \multirow{3}{*}{$\begin{array}{l}\text { MMPI } \\
\text { Scales }\end{array}$} & \multicolumn{4}{|c|}{ Mother's } & \multicolumn{4}{|c|}{ Father's } \\
\hline & \multicolumn{2}{|c|}{ Experimental Group } & \multicolumn{2}{|c|}{ Control Group } & \multicolumn{2}{|c|}{ Experimental Group } & \multicolumn{2}{|c|}{ Control Group } \\
\hline & Means & $\begin{array}{l}\text { Standard } \\
\text { Deviation }\end{array}$ & Means & $\begin{array}{l}\text { Standard } \\
\text { Deviation }\end{array}$ & Means & $\begin{array}{l}\text { Standard } \\
\text { Deviation }\end{array}$ & Means & $\begin{array}{l}\text { Standard } \\
\text { Deviation }\end{array}$ \\
\hline $\mathbf{F}$ & 4.69 & 4.13 & 3.60 & 2.22 & 3.92 & 2.98 & 5.06 & 4.16 \\
\hline $\mathbf{K}$ & 15.00 & 3. 36 & 15.93 & 4.23 & 14.15 & 4.41 & 16.06 & 5.20 \\
\hline Sc i ( $\mathrm{Hs})$ & 15.46 & 4.55 & 17.00 & 6.72 & 12.38 & 4.05 & 11.93 & 2.73 \\
\hline Sc 2 (D) & 24.00 & 4.74 & 22.93 & 7.42 & 20.84 & 5.27 & 18.60 & 3.75 \\
\hline Sc 3 (Hy) & 24.00 & 4.77 & 25.86 & 6.17 & 19.69 & 4.00 & 19.93 & 3.36 \\
\hline Sc $4(\mathrm{Pd})$ & 21.92 & 7.46 & 21.73 & 3.21 & 21.69 & 4.97 & 22.73 & 4.43 \\
\hline Sc 5 (Mf) & 39.23 & 3.13 & 38.46 & 4.48 & 24.46 & 4.89 & 24.53 & 4.32 \\
\hline Sc $6(\mathrm{~Pa})$ & 10.53 & 2.29 & 9.73 & 2.54 & 9.15 & 3.73 & 9.00 & 1.96 \\
\hline Sc $7(P t)$ & 30.84 & 7.35 & 28.46 & 4. & 25.23 & 3.49 & 23.40 & 5.93 \\
\hline Sc $8(S c)$ & 27.23 & 10.47 & 25.46 & 4.70 & 23.84 & 5.12 & 23.93 & 6.44 \\
\hline Sc 9 (MA) & 15.84 & 4.86 & 17.40 & 5.03 & 18.46 & 4.42 & 18.73 & 5.39. \\
\hline Sc 0 (Si) & 33.15 & 9.55 & 28.46 & 8.06 & 33.00 & 10.95 & 24.20 & 7.15 \\
\hline
\end{tabular}

